\title{
Chapter 11 \\ Contribution of Microscopy \\ for Understanding the Mechanism \\ of Action Against Trypanosomatids
}

\author{
Esteban Lozano, Renata Spina, Patricia Barrera, Carlos Tonn, \\ and Miguel A. Sosa
}

\begin{abstract}
Transmission electron microscopy (TEM) has proved to be a useful tool to study the ultrastructural alterations and the target organelles of new antitrypanosomatid drugs. Thus, it has been observed that sesquiterpene lactones induce diverse ultrastructural alterations in both T. cruzi and Leishmania spp., such as cytoplasmic vacuolization, appearance of multilamellar structures, condensation of nuclear DNA, and, in some cases, an important accumulation of lipid vacuoles. This accumulation could be related to apoptotic events. Some of the sesquiterpene lactones (e.g., psilostachyin) have also been demonstrated to cause an intense mitochondrial swelling accompanied by a visible kinetoplast deformation as well as the appearance of multivesicular bodies. This mitochondrial swelling could be related to the generation of oxidative stress and associated to alterations in the ergosterol metabolism. The appearance of multilamellar structures and multiple kinetoplasts and flagella induced by the sesquiterpene lactone psilostachyin $\mathrm{C}$ indicates that this compound would act at the parasite cell cycle level, in an intermediate stage between kinetoplast segregation and nuclear division. In turn, the diterpene lactone icetexane has proved to induce the external membrane budding on T. cruzi together with an apparent disorganization of the pericellar cytoskeleton. Thus, ultrastructural TEM studies allow elucidating the possible mechanisms and the subsequent identification of molecular targets for the action of natural compounds on trypanosomatids.
\end{abstract}

Keywords Natural compounds - Terpenes · Bioactive molecules ·

Trypanosomatids $\cdot$ Trypanosomatid ultrastructure $\cdot$ Neglected tropical diseases

\footnotetext{
E. Lozano

Laboratorio de Inmunología y Desarrollo de Vacunas, Instituto de Medicina y Biología

Experimental de Cuyo (IMBECU, CCT-CONICET), Mendoza, Argentina

R. Spina $\cdot$ P. Barrera $\cdot$ M. A. Sosa $(\bowtie)$

Laboratorio de Biología y Fisiología Celular Dr. Francisco Bertini, Instituto de Histología y

Embriología (IHEM-CONICET), Mendoza, Argentina

e-mail: msosa@fcm.uncu.edu.ar

C. Tonn

Instituto de Investigación en Tecnología Química (INTEQUI), Facultad de Química

Bioquímica y Farmacia, Universidad Nacional de San Luis, San Luis, Argentina
} 


\subsection{Introduction}

Trypanosoma cruzi is the hemoflagellate parasite causative of Chagas' disease. About 6-7 million people are estimated to be infected worldwide, being an endemic disease in Latin America (Andrade et al. 2014; WHO 2017). Both invertebrate (triatomine bugs) and vertebrate (mammals, including man) hosts are needed to complete the parasite's life cycle. T. cruzi has three parasite stages: (a) the amastigote (or spheromastigote), (b) the epimastigote, and (c) the trypomastigote (3). The amastigote is a rounded flagellated form of 2-4 $\mu \mathrm{m}$ diameter which is infective for vertebrate cells (De Souza 2002). The epimastigote is a spindle-shaped organism, 20-40 $\mu \mathrm{m}$ long, with a kinetoplast located in the anterior portion of the parasite. The epimastigote can be found in the hindgut of the insect vector and maintained in vitro in axenic cultures. Both the amastigote and the epimastigote are the replicative forms of the parasite. The trypomastigote is the nonreplicative form and can be found in the tissues and in the bloodstream of the vertebrates and also in the hindgut, the urine, and the feces of the insect vector. In this stage, the kinetoplast is located in the posterior region in relation to the nucleus.

\subsubsection{Life Cycle of Trypanosoma cruzi}

As mentioned above, both invertebrate and vertebrate hosts are needed to complete the life cycle of T. cruzi. When the insect vector ingests the trypomastigote-containing blood from infected mammals, parasites differentiate into replicative epimastigotes within the vector's digestive tract. In the intestine, epimastigotes divide by binary fission and attach themselves to the arthropod's intestinal epithelial cell lining by means of hemidesmosome-like structures. Afterward, a number of epimastigotes undergo metacyclogenesis in the vector's hindgut. Thus, metacyclic trypomastigotes are then eliminated in the feces or the urine (Brack 1968; Garcia and Azambuja 1991; Zeledon et al. 1977; Kolien and Schaub 2000). Following the entrance into the vertebrate host's cells through the bite lesion, trypomastigotes invade neighboring cells and differentiate into amastigotes, and after several cycles of replication, they transform into trypomastigotes, which are responsible for the elimination of the infection.

\subsubsection{Infection and Disease}

In humans, $T$. cruzi can invade any tissue derived either from the embryonic mesoderm, endoderm, or neuroectoderm. However, the extent of the infection depends on the host's genetic background and the parasite strain (Campbell et al. 2004). Mesoderm-derived tissues, such as smooth and striated muscles, bone marrow and the phagocytic mononuclear system, as well as gonadal cells, can be heavily parasitized. Instead, endoderm-derived tissues (liver, kidney, and thyroid gland, among 
others) are seldom parasitized, and even less frequent is the invasion of the neuroectodermal-derived tissues (Campbell et al. 2004). If parasites reach the nervous system, they mostly invade astrocytes (Campbell et al. 2004).

The initial phase (acute phase) of T. cruzi infection lasts between 4 and 8 weeks, whereas the chronic phase persists throughout the patient's lifetime. In addition, the acute phase is mostly asymptomatic or might present as a self-limiting febrile illness. These mild symptoms appear usually about $1-2$ weeks after exposure to the infected vector or up to a few months after transfusion with infected blood (Laranja et al. 1956; Dias 1984; WHO 2002).

The treatment with antiparasitic drugs, such as benznidazole, is known to be effective against the acute phase, preventing subsequent chronic manifestations (Rassi and Luquetti 1992; Pinto et al. 2009). Death in the acute phase occurs occasionally $(<10 \%$ of symptomatic cases) as a result of severe myocarditis and/or meningoencephalitis. Manifestations of the acute disease resolve spontaneously in about $90 \%$ of infected individuals, even if the infection is not treated with trypanocidal drugs. Furthermore, about $60-70 \%$ of these patients never develop a clinical infection, and they enter an "indeterminate form" of chronic Chagas' disease featuring the presence of serum antibodies to the parasite but without clinical manifestations. After 10-30 years after the initial infection, some patients (30-40\%) may develop a chronic disease, characterized by cardiac and/or digestive dysfunction (megaesophagus or megacolon) (Dias 1995).

\subsubsection{Morphology and Ultrastructure of T. cruzi}

\subsubsection{First Transmission Electron Microscopy Studies on T. cruzi}

Since the initial description of T. cruzi by Carlos Chagas in 1909, the morphology of the parasite stages has been the subject of numerous studies. It is noteworthy that T. cruzi has been one of the first cells to be observed by transmission electron microscopy (TEM), and it has been the most studied organism with the techniques developed over the last 50 years (De Souza 2008). Thus, the first electron microscope $(60 \mathrm{kV})$ images of $T$. cruzi were taken by Hertha Meyer and Keith Porter in 1954 (Fig. 11.1) (Meyer and Porter 1954).

However, at that time, the images were of low resolution, and only some peripheral fibrous structures could be observed (Fig. 11.1).

By 1978, samples were examined with a high-voltage electron microscope $(1000 \mathrm{kV})$ (Fig. 11.2) (De Souza 2008), with which the kinetoplast and the attachment of the flagellum to the cell body could be observed. These methods also allowed identifying the unique and highly branched mitochondrion within the parasite.

Over the years, the resolution of the microscope was improved, and the methods became more reliable. Thus, other organelles and structures such as acidocalcisomes, glycosomes, reservosomes, lipid inclusions, and membranous components of the endocytic and secretory machinery could be identified (De Souza 2009). 


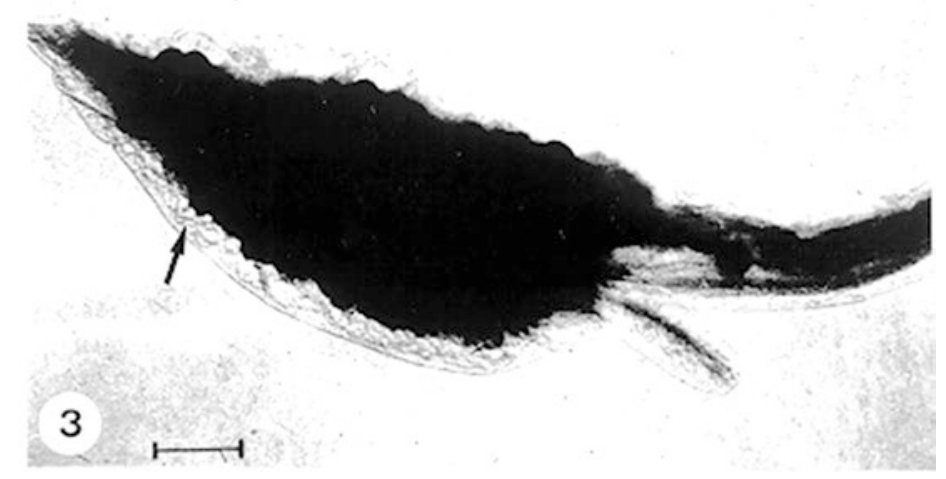

Fig. 11.1 Electron micrograph of the whole epimastigote form of Trypanosoma cruzi dried on the grid. This image was obtained by H Meyer and KR Porter and published in 1954. The arrow indicates peripheral fibrillary structures. Magnification $\times 10,000$



Fig. 11.2 Trypanosoma cruzi trypomastigote observed by high-voltage electron microscopy. Structures such as the kinetoplast $(\mathrm{K})$, the nucleus $(\mathrm{N})$, and areas of adhesion of the flagellum to the cell body (arrows) were identified. Magnification $\times 12,000$ (De Souza 1999)

\subsubsection{The Ultrastructure of T. cruzi}

The nucleus The nucleus of $T$. cruzi and other trypanosomatids has a structural organization that is similar to that of other eukaryotic cells. This organelle is localized centrally in the cell body in the trypomastigote and is elongated, whereas in the amastigote and the epimastigote, it exhibits a more rounded shape (Fig. 11.3). Chromosomal structures have been difficult to describe in T. cruzi due to their incomplete condensation during the mitotic metaphase. The development of novel methods such as the pulsed-field gel electrophoresis (PFGE) has allowed determin- 


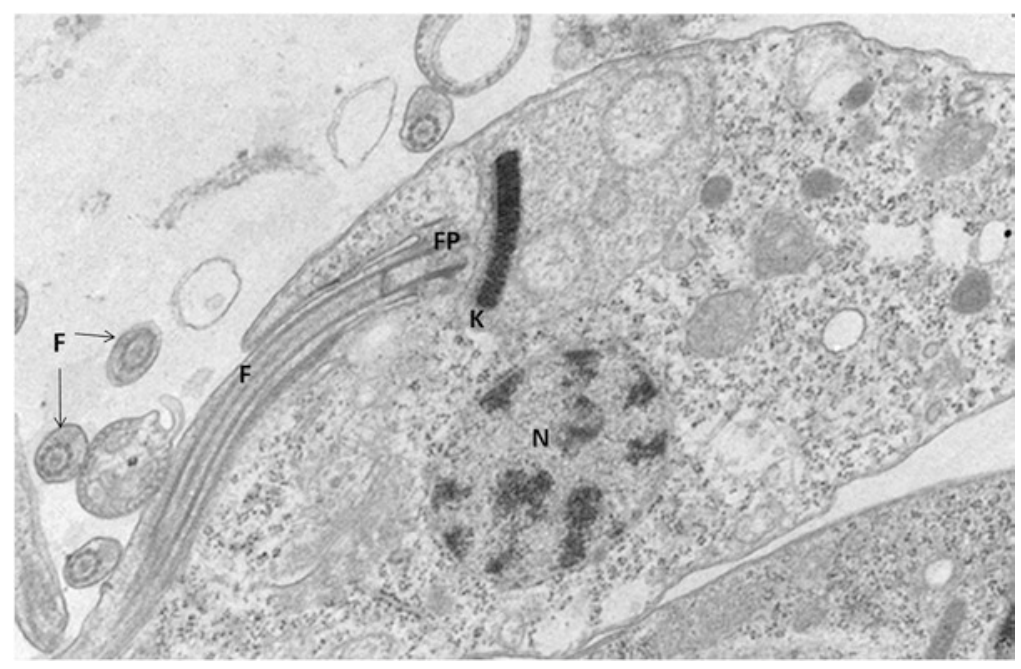

Fig. 11.3 Transmission electron microscopy of a thin section of an epimastigote form of Trypanosoma cruzi. $\mathrm{N}$ nucleus, FP flagellar pocket, $\mathrm{F}$ flagellum, $\mathrm{K}$ kinetoplast, magnification $\times 20,000$

ing the structure of chromosomes, to find that the whole parasite's genome (43$50 \mathrm{Mb}$ ) renders about 30-40 chromosomal bands ranging from 0.45 to $4.0 \mathrm{Mb}$ (Johnston et al. 1999).

The flagellum All members of the Trypanosomatidae family have a single flagellum that emerges from an invagination called the "flagellar pocket" (FP). The flagellum of $T$. cruzi has a basic structure $(9+2)$ of axonemal microtubules which is similar to the typical flagella of other flagellated cells (Fig. 11.3). In trypanosomatids, the length of the flagellum varies in each parasite stage. For example, the amastigote form has a very short flagellum $(1 \mu \mathrm{m})$; however, in the other stages, the parasite elongates, and the flagellum can reach up to about $20 \mu \mathrm{m}$ (MartinezPalomo et al. 1976; De Souza et al. 1978). The flagellum of trypanosomatids is usually attached to the cell body in a specific region. When the flagellum begins to beat, a wave propagates toward its free end, inducing an apparent swing of the parasite body like an undulating membrane. A specialization of the flagellar membrane was described by freeze-fracture at the zone where the flagellum emerges from the cell body both in epimastigotes and trypomastigotes (Martinez-Palomo et al. 1976; De Souza et al. 1978).

The flagellar pocket All trypanosomatids have a FP which is as a depression located at the front of the cell from where the flagellum emerges (Webster and Russel 1993). As shown in Fig. 11.3, the FP is an invagination of the plasma membrane in continuity with the flagellar membrane. Since the plasma and flagellar membranes establish a tight contact at the zone of the flagellum emergence, the FP 
can be considered a special extracellular compartment. There are morphological and biochemical evidences supporting the idea that the FP is a highly specialized compartment of the parasite: (a) the FP is the only area that lacks subpellicular microtubules, (b) its membrane protein composition differs substantially from the plasma membrane surrounding the cell body, and (c) an intense endocytic and exocytic activity occurs in that area (Simpson 1972).

The kinetoplast-mitochondrion complex Early electron microscopy studies had identified an electrodense and slightly bent structure named kinetonucleus (Meyer et al. 1958). Later on, this structure was termed the kinetoplast. This structure is located close to the nucleus, and its shape and the structural organization vary according to parasite stage (Fig. 11.3). Not until the late 1960s was the molecular configuration of kinetoplast DNA unveiled (Shapiro and Englund 1995; Lukes et al. 2002). It is now well established that trypanosomatids have a single and highly branched mitochondrion, whose DNA (k-DNA) forms the dense structure of the kinetoplast. The first images obtained using thin sections clearly revealed the special organization of the k-DNA located in a specialized zone of the mitochondrial matrix, perpendicular to the flagellum axis. In addition, filamentous structures connect the kinetoplast to the basal body (Souto-Padron et al. 1984; Ogbadoiyi et al. 2003).

Other cytochemistry studies, using the ethanolic phosphotungstic acid technique and ammoniacal silver, have demonstrated the presence of basic proteins in the kinetoplast, suggesting that these proteins may neutralize the negatively charged DNA molecules packed within this structure (Souto-Padron and De Souza 1978; Souto-Padron and De Souza 1979). More recently, the presence of these basic proteins was confirmed by biochemical and molecular studies and indicated that $\mathrm{H} 1$ histone-like proteins participate in the condensation of k-DNA in Crithidia fasciculata and T. cruzi (De Souza and Cavalcanti 2008).

Two types of DNA rings are present in the kinetoplast: the minicircles and the maxicircles. There are several thousand minicircles which range in size from about 0.5 to $2.5 \mathrm{~kb}$ (depending on the species) and a few dozen maxicircles, usually varying from 20 to $40 \mathrm{~kb}$ (Shapiro and Englund 1995; De Souza and Cavalcanti 2008). These DNA rings encode guide RNAs that modify maxicircle transcripts by extensive uridylate insertion or deletion, a process known as "RNA editing." In turn, the maxicircles are structurally and functionally analogous to the mitochondrial DNA of higher eukaryotes, which encodes rRNAs and the subunits of respiratory chain complexes.

The endomembrane system In trypanosomatids, the endoplasmic reticulum (ER) is observed throughout the protozoan cytoplasm. In some cases the ER reaches the cell periphery establishing contact with the plasma membrane and the subpellicular microtubules (Pimenta and De Souza 1983). In turn, cisternae of the Golgi complex, which vary in size according to the species, are observed near the kinetoplast and the FP (Fig. 11.4). These cisternae are oriented perpendicularly to the kinetoplast and parallel to the FP. Vesicle budding from the trans-Golgi is also observed in the vicinity of the FP. It has been demonstrated that an increase in the number of Golgi 




Fig. 11.4 Transmission electron microscopy of a thin section of an epimastigote form of Trypanosoma cruzi. N nucleus, F flagellum, K kinetoplast, G Golgi complex. Magnification $\times 20,000$

cisternae is related to the acquisition of epimastigote resistance to a cysteine protease inhibitor (Engel et al. 2000).

The glycosome In several species of trypanosomatids, ultrastructural studies have revealed the presence of spherical structures that have a homogeneous matrix and are surrounded by a single membrane. Initially, these structures were named microbodies, in analogy with similar structures described in mammalian cells. Interestingly, in trypanosomatids, most of the glycolytic pathway is carried out in this organelle, whereas in other eukaryotic cells the glycolysis occurs in the cytoplasm. Thus, these microbodies were eventually named glycosomes (Opperdoes and Borst 1977). Biochemical studies have demonstrated that glycosomes contain enzymes of high isoelectric point (Souto-Padron and De Souza 1978). There is also evidence that in trypanosomatids, additional metabolic pathways, such as carbon dioxide fixation, purine salvage and de novo pyrimidine biosynthesis, fatty acid elongation, isoprenoid biosynthesis, and sterol biosynthesis, take place in the glycosomes, while these processes occur in the cytosol of other cell types (Opperdoes 1987; Opperdoes and Cotton 1982).

The acidocalcisome Observations of thin sections of T. cruzi and other trypanosomatids have revealed some vacuolar structures containing electron-dense deposits. These structures were first identified as polyphosphate or volutin granules. In 1994, this organelle was demonstrated to transport protons and calcium, and therefore, it was named the acidocalcisome (Docampo et al. 2005). The appearance of this organelle depends on the method used to prepare the samples for electron microscopy. If conventional methods are used, it appears that the electron-dense deposits 


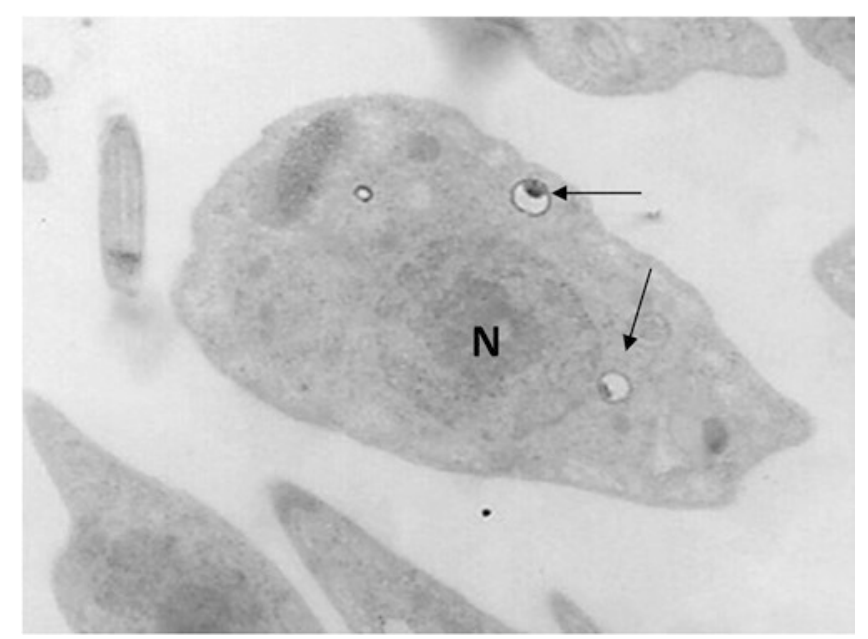

Fig. 11.5 Transmission electron microscopy of a thin section of an epimastigote form of Trypanosoma cruzi. N nucleus. Arrows indicate the acidocalcisomes. Magnification ×5,000

shrink to such an extent that only a small dark spot is observed inside the organelle (Fig. 11.5). Instead, most of the electron-dense deposits are preserved if cryofixation is used or when cells are quick frozen using a high-pressure freezing technique and subjected to freeze-substitution (Miranda et al. 2000). The best strategy to visualize the acidocalcisome is to observe the whole cells dried on a grid under an electron microscope with an energy filter. Furthermore, the electron microscopy microanalysis has played a key role in determining the ionic composition of the acidocalcisome. At present, it is known that the acidocalcisome contains calcium, phosphorous, sodium, potassium, and zinc, and in some trypanosomatids (such as $T$. cruzi, T. brucei, L. amazonensis, and L. donovani), iron has also been found (Miranda et al. 2004). Therefore, it is postulated that the acidocalcisome is involved in functions such as (i) the storage of calcium, magnesium, sodium, potassium, zinc, iron, and phosphorous compounds, especially inorganic pyrophosphate and polyphosphate, (ii) the $\mathrm{pH}$ balance, and (iii) the osmoregulation, possibly acting in close association with a contractile vacuole (Docampo et al. 2005).

The contractile vacuole This structure is formed by several tubules connected to a central vacuole located close to the FP (Linder and Staehelin 1977). More recently, aquaporin, a protein involved in water transport, was identified in both, the acidocalcisome and the contractile vacuole of T. cruzi epimastigotes (Montalvetti et al. 2004). These structures appear to be involved in osmoregulation processes. 




Fig. 11.6 Schematic representation of morphological changes during the Trypanosoma cruzi cell cycle. The stages of the nuclear cell cycle are indicated as G1, S, G2, and M (mitosis).The shading inside the nucleus and kinetoplast is proportional to the DNA content. The new flagellum is shown in gray and the old in black. The new flagellum emerges from the flagellar pocket when cells are in the G2 stage, and at this stage, the kinetoplast segregates. Mitosis occurs, the flagellar pocket segregates, and the cell undergoes cytokinesis, producing two identical cells. N nucleus, K kinetoplast, F flagellum, FP flagellar pocket (Elias et al. 2007)

\subsubsection{Ultrastructure of $T$. cruzi During Cell Division}

Unlike other cell types, a disruption of the nuclear membrane has not been observed in T. cruzi during cell division (Fig. 11.6), making it difficult to distinguish the typical mitosis steps. In spite of this drawback, the formation of a mitotic spindle has been observed inside the parasite's nucleus. At the beginning of division, the first signals can be observed in the nucleus; the chromatin material localized below the inner nuclear membrane and the nucleolus disappear. This occurs immediately after replication of the basal body, when the kinetoplast still shows no morphological signs of division. The nucleus changes from a spherical to an oval form (De Souza and Meyer 1975; Solari 1980).

Likewise, during division, small electron-dense plaques are observed between and connected with the intranuclear microtubules (De Souza and Meyer 1975; Solari 1980). A more detailed description of the nuclear division of T. cruzi epimastigotes arises from serial sections and a three-dimensional reconstruction of each stage (Solari 1980). The mitotic spindle is formed by approximately 120 microtubules arranged in two sets of about 60 , running from each pole to the dense plaques and divided into discreet bundles which reach a single plaque. Each plaque has a 
symmetrical structure formed by transverse bands. Before nuclear elongation occurs, the dense plaques split in two halves and begin to migrate to the polar regions. At this time no microtubules are seen between the two halves of each plaque. All microtubules are localized between the plaques and the poles of the nucleus. The nature and functional roles of the dense plaques are not yet clear. It has been suggested that they could represent specialized parts of uncondensed chromosomes (Solari 1980). However, there are no data supporting this hypothesis. They could also represent kinetochore-like structures which would play an important role in separation of the nuclear material between two new cells. When the division is completed, the chromatin and the nucleolus reorganize and assume the position seen in interphase cells, whereas the microtubules disappear. During the whole process of division, the nuclear membrane remains intact, albeit with a more irregular folding. Recent studies have shown that a nucleolus is not observed in the trypomastigote and that there is a decrease in the transcription rates by RNA polymerases I and II from the epimastigote to the trypomastigote form (Elias et al. 2001).

\subsection{How Vulnerable Is T. cruzi?}

Chagas' disease is a widely distributed illness that affects many people and whose cure is far from being achieved. Traditionally, the development of new drugs has been based on the screening of natural compounds or extracts containing bioactive molecules against certain pathogens, including $T$. cruzi. Over the years, this random approach has been conducted without prior knowledge neither of the molecular targets on the pathogen nor of the mechanism of action of drugs. Nowadays, the search for antiparasitic molecules is accompanied by more extensive studies in order to know the impact of the compound on certain molecular targets. Making use of the extensive knowledge of the T. cruzi genome and its biochemistry, the mechanism of action of the new bioactive molecules could be better understood (El Sayed et al. 2005). Thereafter, the molecular targets have been selected on the basis of their role in the parasite growth and survival. In recent years, the gene knockout technology has been employed to study the function of a particular gene, thus being an excellent method for selecting and validating a molecular target. Afterward, inhibitory molecules are designed for these molecular targets (Majumder 2008).

\subsubsection{Some Molecular Targets for Trypanocidal Agents}

\subsubsection{Ergosterol Biosynthesis}

Since trypanosomatid parasites lack the abundant supply of cholesterol present in the mammalian host cells (Urbina 1997; Urbina 2000; Urbina 2001; Urbina 2002), they have a strict requirement for specific endogenous sterols (e.g., 
ergosterol and analogs) for survival and growth. Inhibitors of the ergosterol biosynthesis can induce radical parasitological cure in animal models suffering both acute and chronic experimental T. cruzi infection and are also active against several forms of leishmaniasis (Urbina 1997; Urbina 2000; Urbina 2001; Urbina 2002). One of the crucial enzymes that regulates the sterol synthesis is the squalene synthase (SQS), which catalyzes the dimerization of farnesyl pyrophosphate (FPP) in a two-step reaction to form squalene (Gonzalez-Pacanowska et al. 1988). Therefore, SQS is currently under intense study, since it is a possible molecular target for the action of compounds that interfere with the synthesis of cholesterol in humans (Bergstrom et al. 1995). Studies in vertebrates and yeasts have demonstrated that the levels of SQS mRNA change in response to exogenous sources of sterols and also to 3-hydroxy-3-methylglutaryl coenzyme A (HMG-CoA) reductase inhibitors.

\subsubsection{The Thiols Metabolism and the Defense Against Free Radicals}

In $T$. cruzi, the defense mechanisms against the oxidative stress are deficient when compared to that of mammals. This feature is due to a low superoxide dismutase activity (Turrens 2004) and the absence of glutathione peroxidase, catalase (Turrens 2004; Wilkinson and Kelly 2003), $\alpha$-tocopherol, and $\beta$-carotene (Aldunate and Morello 1993) in trypanosomatids. Thus, the defense against oxidative stress is limited to GSH and trypanothione (N1, N8-bis (glutathionyl) spermidine) (T(SH)2), the latter being exclusive of trypanosomatids and indispensable for glutathione reduction (Ariyanayagam and Fairlamb 2001; Turrens 2004). This characteristic makes T. cruzi more vulnerable than the host cells to the oxidative stress. This is the basis of the action of nifurtimox and benznidazole, which, through electrophilic conjugation, these drugs block the thiol groups in the parasites (Ariyanayagam et al. 2003; Maya et al. 1997). In mammals, however, the eventual decrease of GSH caused by these compounds is compensated by $\alpha$-tocopherol, $\beta$-carotene, and ascorbate, among others.

\subsubsection{Cruzipain}

Cruzipain $(\mathrm{Cz})$ is a cysteine protease $(\mathrm{CP})$ that belongs to the papain superfamily in mammals. This enzyme contains an unusual C-terminal extension, as other CPs from trypanosomatids. This glycoprotein is synthesized as a zymogen that is activated by cleavage of the $\mathrm{N}$-terminal pro-domain to generate the mature protease (Eakin et al. 1992). The mature enzyme consists of a catalytic moiety at the $\mathrm{N}$-terminus, displaying a high homology with cathepsin L, and a C-terminus showing 36\% homology with that of type 1 CPs from other protozoans (Campetella et al. 1992; Mottram et al. 1998). Cz seems to be important for the survival of the parasite and for the growth and cellular differentiation (dos Reis et al. 2006; McKerrow et al. 2006). This enzyme has endopeptidase activity and 
hydrolyzes the $\mathrm{IgG} \mathrm{Fc}$ fragment, endowing the parasite with an escape mechanism from the host's immune attack (Bontempi and Cazzulo 1990). Cz has also been demonstrated to play a role in the internalization of the parasite into mammalian cells, a process for which specific enzyme inhibitors have been found, thus inhibiting T. cruzi intracellular replication (Souto-Padron et al. 1990; Meirelles et al. 1992).

\subsubsection{Nucleotide Metabolism}

It is known that trypanosomatids cannot synthesize purines de novo. However, they have developed effective mechanisms for self-delivery of preformed purines and nucleosides. Through the salvage pathway, the parasite is able to concentrate pyrazolopyrimidines and transform them into purines for the synthesis of nucleic acids (Gutteridge and Davies 1981).

The pyrazolopyrimidine base allopurinol (4-hydroxypyrazolo [3,4-a] pyrimidine, HPP) is activated by the phosphoribosyl transferase into the ribonucleotide-5' monophosphate (HPPR-MP). HPPR-MP is then amined to 4-aminopyrazolopyrimidine ribonucleotide (APPR-MP) and subsequently phosphorylated to form the triphosphate form. The growth of $T$. cruzi epimastigotes is inhibited by allopurinol; however, some strains are not sensitive to this compound, suggesting that these strains have different metabolic routes (Avila et al. 1984; Avila and Avila 1981; Marr et al. 1978). On the other hand, pyrimidines can be synthesized by trypanosomes de novo, and it is known that some of the enzymes involved in such pathways are located in glycosomes, whereas the analogous enzymes in mammals are cytosolic (Hammond et al. 1981).

\subsection{In the Search for a Solution Against Parasitic Diseases}

Chagas' disease and leishmaniasis cause significant morbidity and mortality in Latin America and are extending worldwide. According to the World Health Organization (WHO), these diseases are considered neglected tropical diseases (NTDs), affecting people in developing countries.

Most of the drugs currently used for the treatment of Chagas' disease and leishmaniasis have severe side effects. Currently, the treatments against Chagas' disease are limited to benznidazole and nifurtimox, which have been available since the 1970s. These two drugs are effective only in the acute phase of the disease. On the other hand, the current antileishmanial therapy includes the use of pentavalent antimonials (amphotericin B, miltefosine, and paromomycin), which also present several disadvantages such as the route of administration, the development of parasite resistance, the high costs, the teratogenic effects, and the treatment duration and 
associated toxicity. Among the natural compounds, the members of the large family of terpenoids display a wide range of biological activities such as anticancer and anti-inflammatory and are effective against various infective agents such as viruses, bacteria, and parasites (Sepúlveda-Boza and Cassels 1996). In fact, several terpenoids have proved to be active against $T$. cruzi and Leishmania spp., thus being attractive compounds as future therapeutic agents for Chagas' disease and leishmaniasis (Barrera et al. 2008). Besides, terpenoids are widely distributed in the plant kingdom. In the following sections, we will review the antiprotozoal activity of natural terpenoid compounds and derivatives isolated from plants in Argentina.

Terpenes are made up of isoprene $\left(\mathrm{C}_{5} \mathrm{H}_{8}\right)$ units. According to the number of linked isoprenes, several terpene families are defined. Among them, sesquiterpenes that contain three $\left(\mathrm{C}_{15} \mathrm{H}_{24}\right)$ and diterpenes that contain four $\left(\mathrm{C}_{20} \mathrm{H}_{32}\right)$ isoterpene units are the aim of this revision.

\subsubsection{Sesquiterpene Lactones}

Dehydroleucodine (DHL) is a sesquiterpene lactone (STL) belonging to the guaianolide group (Fig. 11.7). This compound has been isolated and purified at concentrations $>1 \%$ from the aerial parts of Artemisia douglasiana, which is a widespread medicinal plant commonly used in Argentina (Giordano et al. 1990). In addition, other biological activities have been described for this compound (Penissi et al. 2003; Costantino et al. 2016). Mexicanin (MXN) is a STL isolated from the aerial parts of Gaillardia megapotamica (Jimenez-Ortiz et al. 2005) (Fig. 11.7).

Psilostachyin (Psi) and psilostachyin C (Psi C) have been isolated by bioassayguided fractionation from Ambrosia tenuifolia and Ambrosia scabra (Asteraceae), respectively. These medicinal species are popularly known as "ajenjo del campo" and traditionally used against intermittent fevers and worm infections (Sülsen et al. 2006; Muschietti et al. 2008). Parthenolide has been isolated and purified from the aerial parts of Tanacetum parthenium (Tiuman et al. 2005). Cynaropicrin has been isolated from aerial parts of Cynara cardunculus var. scolymus ("globe artichoke"), which belongs to the Asteraceae family (da Silva et al. 2013) (Fig. 11.7).

\subsubsection{Diterpenes}

5-epi-icetexone (ICTX) is a diterpene isolated from the aerial parts of Salvia gilliesii as an orange solid (Nieto et al. 2000). Abietane (12-hydroxy-11,14-diketo6,8,12-abietatrien-19,20-olide) (HABTO) has been isolated from the aerial parts of Salvia cuspidata. This compound has a diterpene structure belonging to the abietane group (Lozano et al. 2015) (Fig. 11.8). 

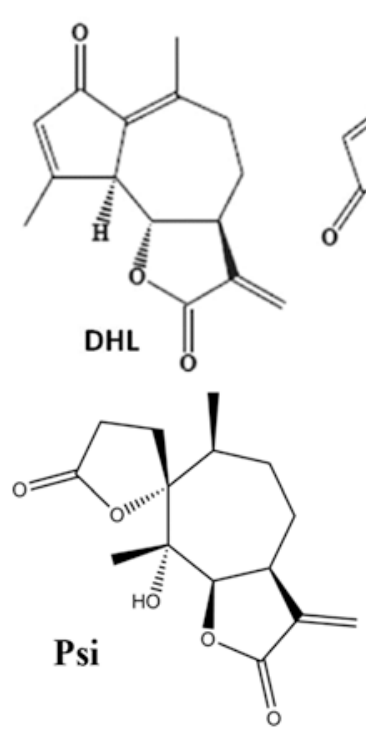
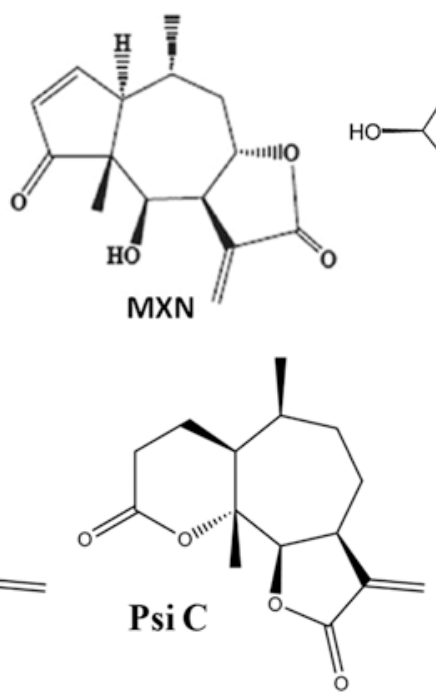

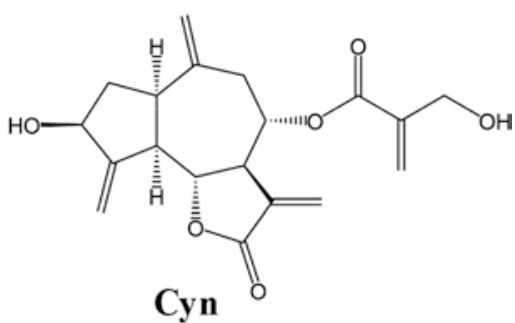

Fig. 11.7 Chemical structure of sesquiterpene lactones. DHL Dehydroleucodine, MXN Mexicanin, Cyn Cynaropicrin, Psi Psilostachyin, Psi C Psilostachyin C, Par Parthenolide

Fig. 11.8 Chemical structure of natural diterpenes. 5-epi-icetexone (ICTX) and abietane (12-hydroxy-11,14-diketo6,8,12-abietatrien-19,20olide) (HABTO)
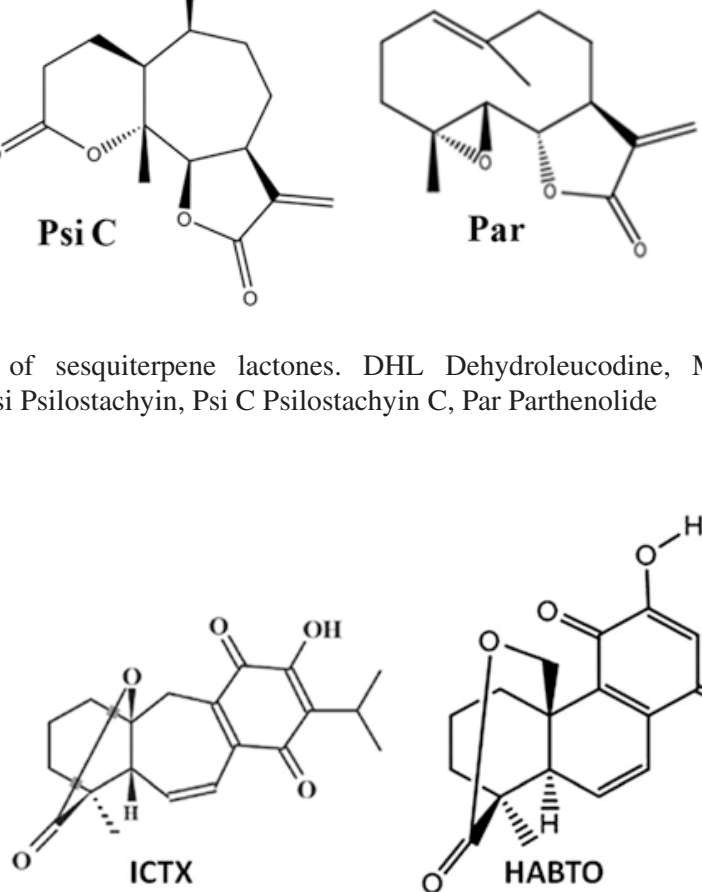

\subsubsection{Effect of Sesquiterpene Lactones and Diterpenes on Trypanosoma cruzi}

All the compounds mentioned above are active against different stages of T. cruzi, inhibiting their growth and viability and with a very low toxicity on mammalian cells (Brengio et al. 2000; Jimenez-Ortiz et al. 2005; Lozano et al. 2012b). Because of this, these molecules could be potential therapeutic agents against these parasitic diseases. Sesquiterpene lactones have proved to have oxidative effects on the parasites, and this effect could be ascribed to the presence of the $\gamma$-lactone group (Giordano et al. 1992; Jimenez-Ortiz et al. 2005). Several studies 


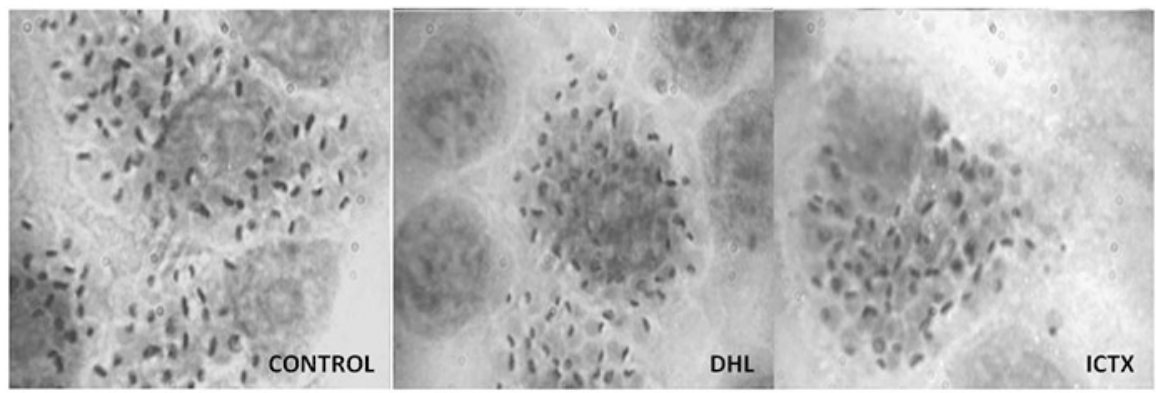

Fig. 11.9 Vero cells infected with Trypanosoma cruzi, subjected to different treatments with dehydroleucodine (DHL) or 5-epi-icetexone (ICTX) (Lozano et al. 2012b)

have suggested that STLs and ICTX may act through multiple mechanisms on different parasite molecular targets (Barrera et al. 2008; Jimenez-Ortiz et al. 2005; Lozano et al. 2012a). DHL and ICTX have also effect on the growth of intracellular forms of T. cruzi, without affecting the viability of the host cell (Fig. 11.9) (Lozano et al. 2012b). In animal models, it has been demonstrated that ICTX can protect mice from $T$. cruzi, at least during the early stages of infection (Fig. 11.10) (Lozano et al. 2016).

Morphological and ultrastructural studies have been very helpful in elucidating the possible mechanisms of action of drugs on trypanosomatids. Some examples of the action of STL and diterpenes on T. cruzi epimastigotes are described in the following sections.

While DHL does not induce major changes on the morphology or the ultrastructure of the parasites (Fig. 11.11), MXN has been demonstrated to induce vacuolization in the cytoplasm, which precedes parasite death (Fig. 11.12).

The nuclear disorganization observed by TEM may show an apoptotic effect of the drugs on the parasites. It is feasible that MXN causes irreversible damage to the parasite DNA, since interactions of STLs with DNA have been reported (Lee et al. 1977). However, it was not possible to discern whether this nuclear disorganization preceded other effects, such as vacuolization and changes in morphology, or if all these drastic changes occurred simultaneously.

Psilostachyins, isolated from Ambrosia tenuifolia (Sülsen et al. 2010), have been found to be active against T. cruzi epimastigotes. This STL induced drastic ultrastructural changes, such as cytoplasmic vacuolization, a slight increase in multivesicular bodies, and, especially, mitochondrial swelling accompanied by a visible deformity of the kinetoplast (Fig. 11.13). The mitochondrial swelling may be attributed to alterations in ergosterol metabolism, as reported by others (Lazardi et al. 1990).

Psilostachyin C, isolated from Ambrosia scabra, is also active against T. cruzi epimastigotes since it induces alterations on $T$. cruzi ultrastructure, such as cytoplasmic vacuolization, at a concentration of $2.5 \mu \mathrm{g} / \mathrm{ml}$. Moreover, the compound promoted the appearance of membranous structures resembling cytoplasmic multivesicular bodies (Fig. 11.14d). The appearance of multilamellar structures was 


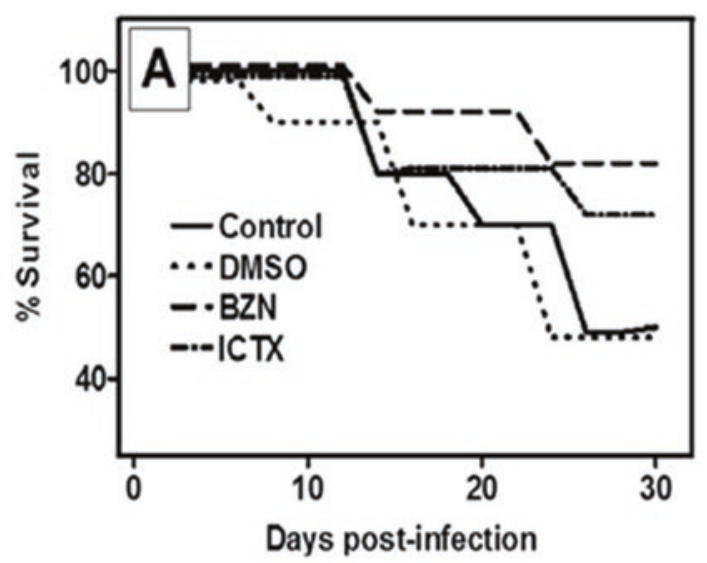

B

HEART
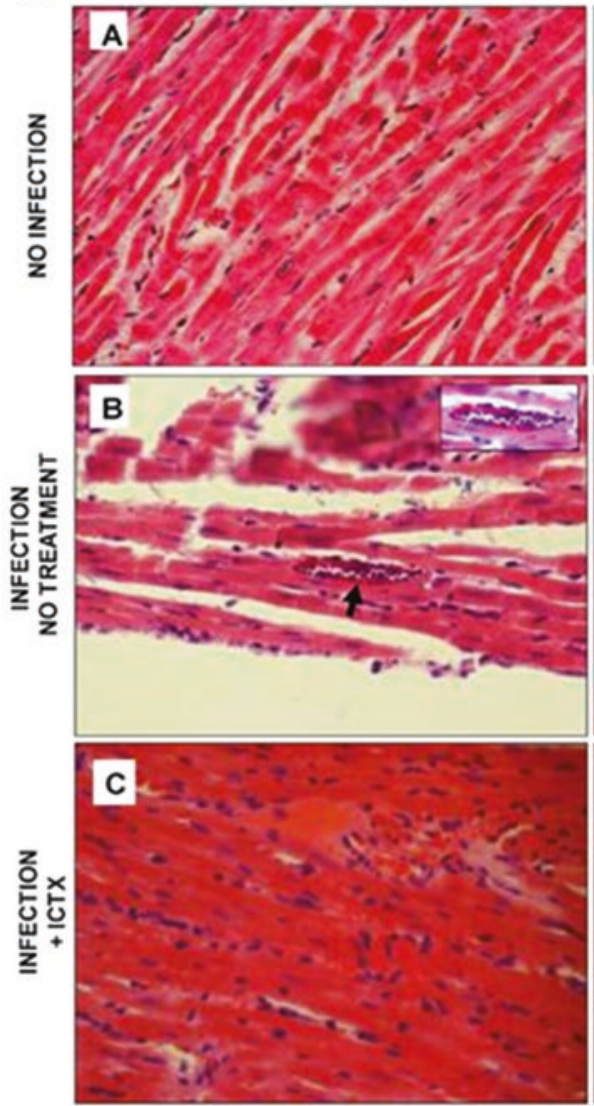

SKELETAL MUSCLE
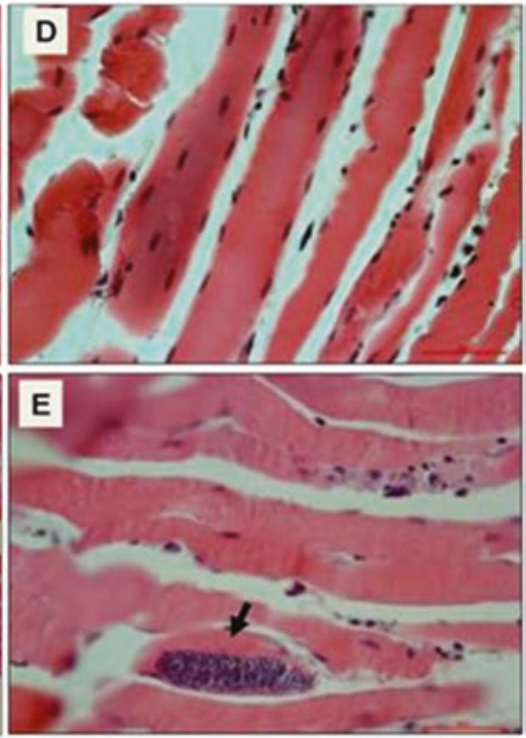

F

Fig. 11.10 (a) Survival of mice infected with T. cruzi and treated with either benznidazole (BZN) or 5-epi-icetexone (ICTX). (b) Histological analysis of cardiac muscle (a-c) or skeletal muscle of the hind leg (d-f) in mice inoculated with T. cruzi and treated or not with either BZN or ICTX on day 35 after infection. Amastigote nests (b, arrow and inset, e arrow) can be observed in control animals. Magnification $\times 400$ (Lozano et al. 2016) 



Fig. 11.11 Ultrastructural aspect of cultured Trypanosoma cruzi on the second day of growth in culture medium. (a) Control cells and (b) cells incubated with $10 \mu \mathrm{g} / \mathrm{ml}$ dehydroleucodine (DHL). $\mathrm{N}$ nucleus, K kinetoplast (Brengio et al. 2000)

also observed. Although some parasites exhibited redistribution of nuclear chromatin, the compound did not induce changes on cellular or nuclear morphology. Interestingly, some parasites (ca. 10\%) exhibited abnormalities such as the presence of more than two flagella and kinetoplasts (Fig. 11.14b, c), suggesting a possible effect of the compound on cytokinesis (Sülsen et al. 2011).

Ultrastructural analysis of cynaropicrin-treated bloodstream trypomastigotes (BT) demonstrated that while untreated parasites exhibited normal morphology for the mitochondrion, nucleus, endoplasmic reticulum, and kinetoplast (Fig. 11.15a, b), 


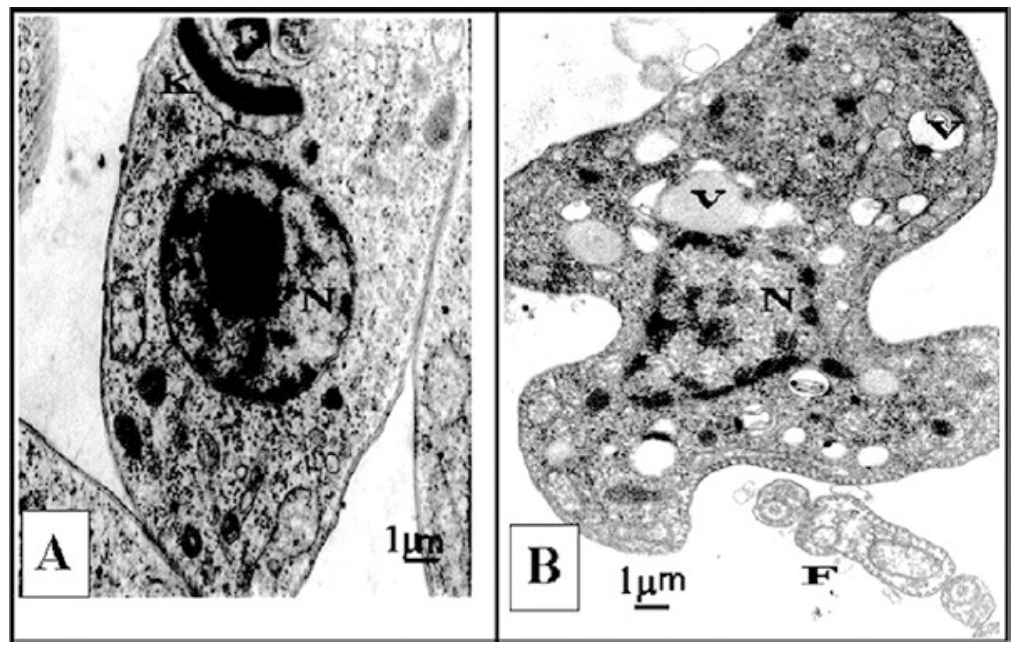

Fig. 11.12 Ultrastructure of Trypanosoma cruzi epimastigotes on the second day of growth in culture medium. (a) Control cells or (b) cells incubated with $1.9 \mu \mathrm{M}$ Mexicanin (MXN). N nucleus, K kinetoplast, F flagellum, V vacuoles. Magnification 35,000 (Jimenez-Ortiz et al. 2005)

cynaropicrin-treated BT showed intense intracellular vacuolization, with a great number of membrane blebs and with shedding of the intracellular contents, alongside the occurrence of large multivesicular bodies (Fig. 11.15c-f) (da Silva et al. 2013).

Some diterpenes containing icetexane skeleton, such as 5-epi-icetexone (ICTX), are also active against $T$. cruzi. Interestingly, after $24 \mathrm{~h}$ of exposure to ICTX, some parasites exhibit an external vesiculization and an apparent disorganization of the pericellar cytoskeleton although cell integrity is apparently preserved (Fig. 11.16c). At longer times of exposure to the drug, the parasites showed an intense vacuolization in the cytoplasm and exhibited a nuclear disorganization, as a signal of the deleterious effect of the compound (Fig. 11.16d). The external vesiculization observed at $24 \mathrm{~h}$ of exposure may be related to a disorganization of the cytoskeleton surrounding the parasites. It is known that the presence of a microtubules layer localized below the parasite plasma membrane confers rigidity and high resistance to mechanical traction. The vacuolization may be related to strong alterations of metabolism and/or the ionic equilibrium, as well as membrane disruptions due to lipid peroxidation (Brengio et al. 2000).

As mentioned above, it has been difficult to detail the stages of cell division of the parasites because of the insufficient chromatin condensation, the maintenance of the nuclear envelope, and the lack of a visible mitotic spindle. Nevertheless, it has been possible to specify a sequence of events that precede the cellular division: duplication of the flagellum, followed by kinetoplast duplication and finally the nuclear division (De Souza and Meyer 1975; Elias et al. 2001). In axenic cultures, the parasites grow asynchronously, and therefore, strategies have to be used to achieve growth synchronization, such as the use of hydroxyurea (HU). By this strat- 


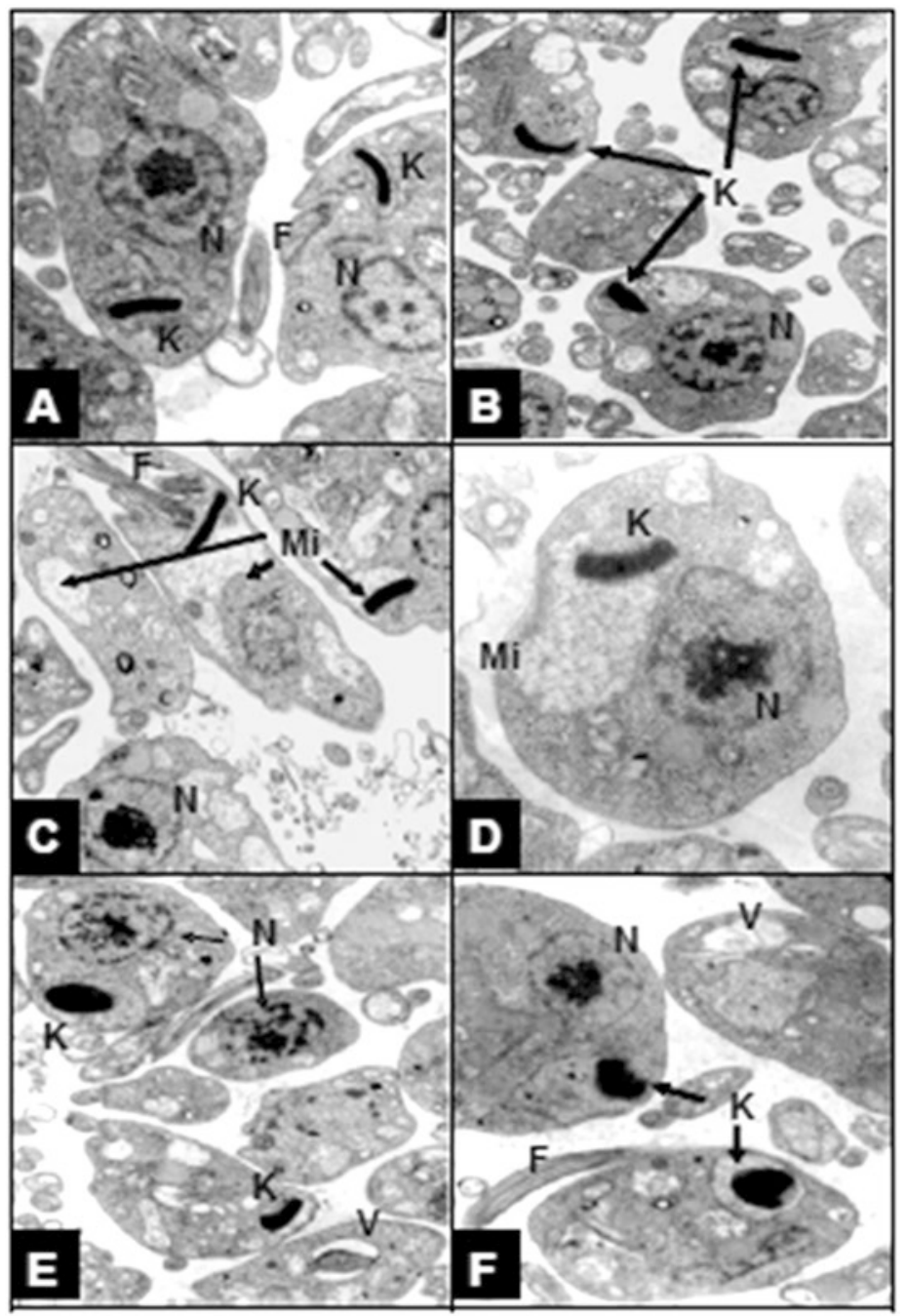

Fig. 11.13 Effect of psilostachyin on the ultrastructure of Trypanosoma cruzi epimastigotes. Parasites were incubated in Diamond's medium alone (a) or with the addition of $0.5(\mathbf{b}, \mathbf{c}), 1.0(\mathbf{d}$, e) or 2.5 (f) $\mu \mathrm{g} / \mathrm{ml}$ of psilostachyin. $\mathrm{N}$ nucleus, $\mathrm{K}$ kinetoplast, F flagellum, V vacuoles, Mi mitochondrion. Magnification $\times 2500$ (B, C, E), $\times 2800$ (a, f), and ×3000 (d) (Sülsen et al. 2010) 


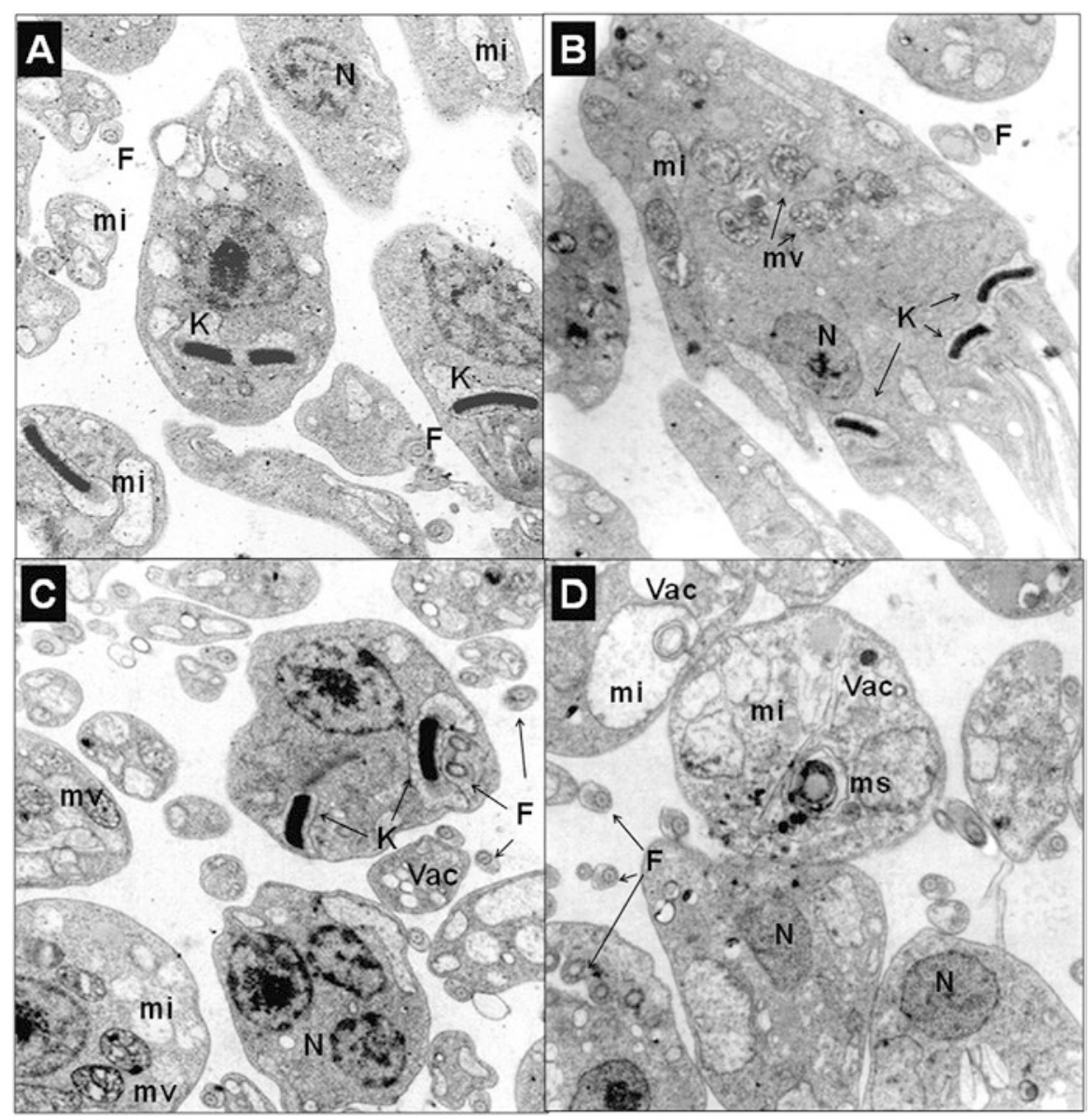

Fig. 11.14 Ultrastructural effects of psilostachyin C on Trypanosoma cruzi epimastigotes. Parasites were incubated with (a) Diamond's medium alone or with (b) $0.5 \mu \mathrm{g} / \mathrm{ml}$ psilostachyin C, (c) $1.0 \mu \mathrm{g} / \mathrm{mL}$ psilostachyin C, or (d) $2.5 \mu \mathrm{g} / \mathrm{ml}$ psilostachyin C. N nucleus, K kinetoplast, F flagellum, Vac vacuoles, mi mitochondria, ms multilamellar structures, mv multivesicular bodies. Magnification $\times 2500$ (Sülsen et al. 2011) 


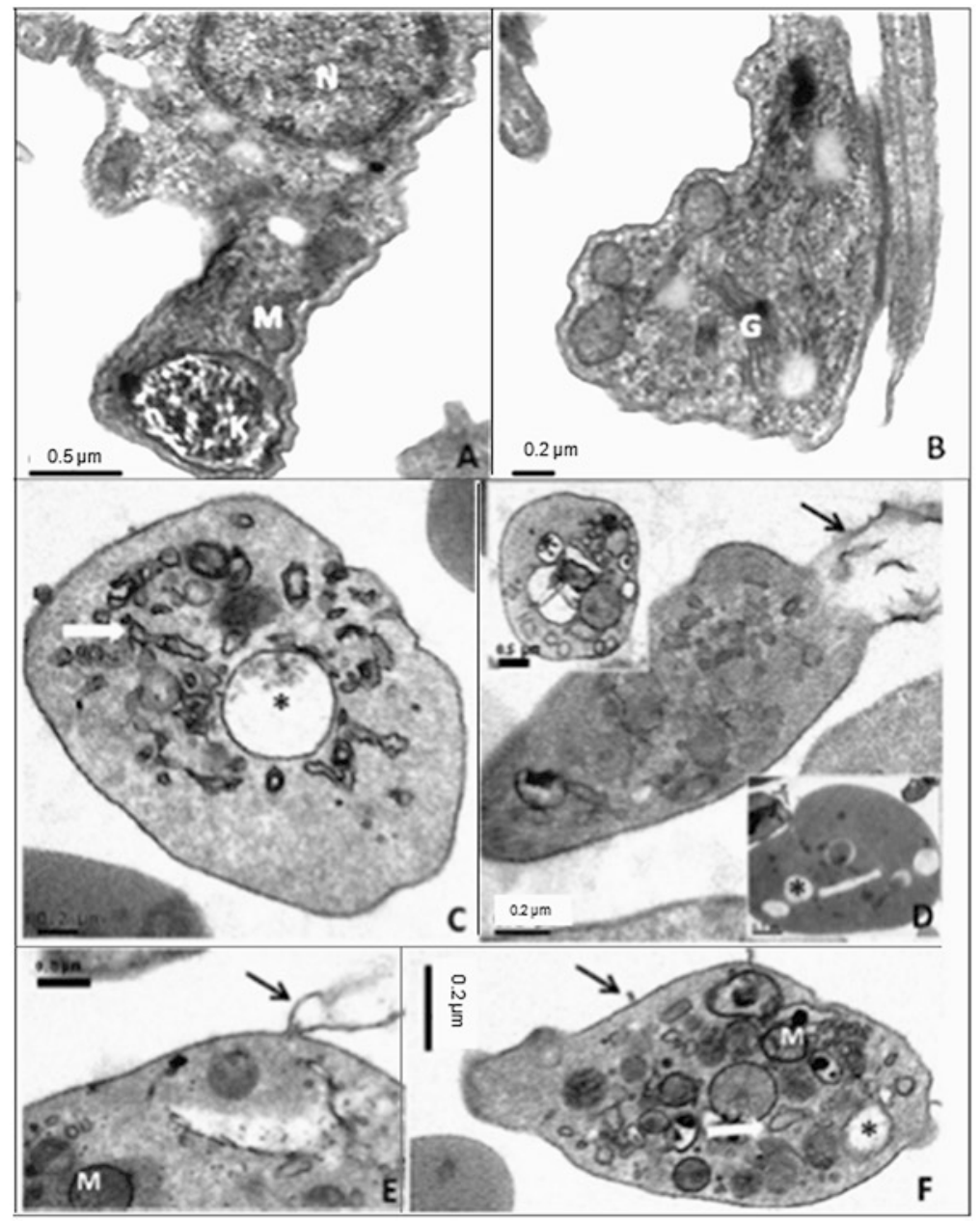

Fig. 11.15 Transmission electron microscopy analysis of the effect of cynaropicrin on bloodstream trypomastigotes. BT were left untreated (a and b) or exposed to this STL $\left(\mathrm{EC}_{50} / 24 \mathrm{~h}\right.$ ) for $2 \mathrm{~h}(\mathbf{c}-\mathbf{f})$. Untreated parasites displayed typical morphology, while cynaropicrin-treated parasites showed vacuolization $(*)$, swelling of the mitochondrion and endoplasmic reticulum (white arrows), and plasma membrane shedding (black arrows). M mitochondrion, G Golgi complex, $\mathrm{N}$ nucleus (da Silva et al. 2013) 


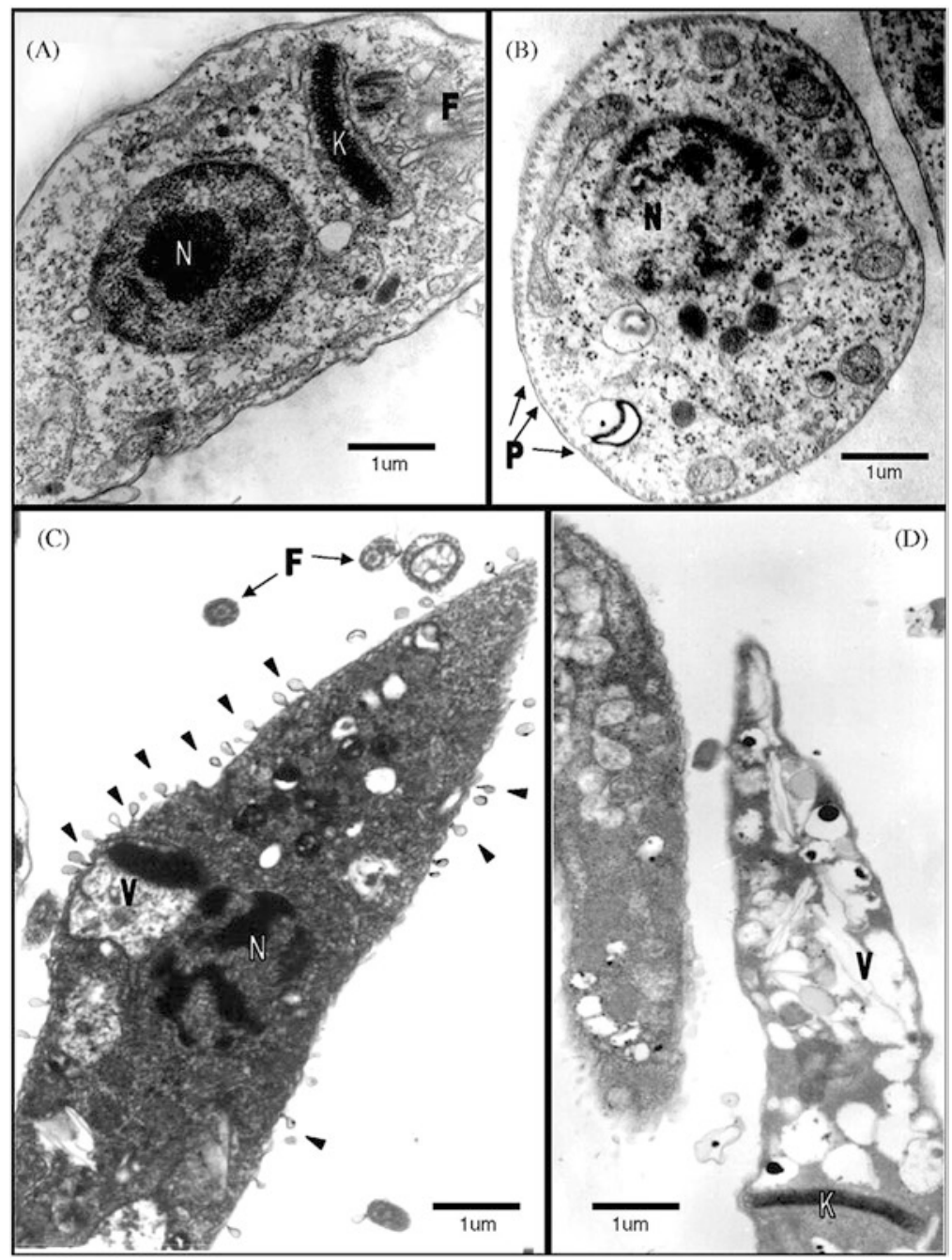

Fig. 11.16 Effect of 5-epi-icetexone (ICTX) on the ultrastructure of Trypanosoma cruzi epimastigotes after incubation for $24 \mathrm{~h}(\mathbf{c})$ or $48 \mathrm{~h}(\mathbf{d})$ in the presence of $4.3 \mu \mathrm{M}$ of ICTX. (a and $\mathbf{b})$ : untreated controls. $\mathrm{N}$ nucleus, $\mathrm{K}$ kinetoplast, $\mathrm{P}$ pericellar cytoskeleton, $\mathrm{V}$ vacuoles, $\mathrm{F}$ flagellum. Arrowheads indicate vesiculization processes. Magnification: $\times 5000$ (a and b) $\times \times 4500(\mathbf{c}) ; \times 3500$ (d) (Sanchez et al. 2006) 


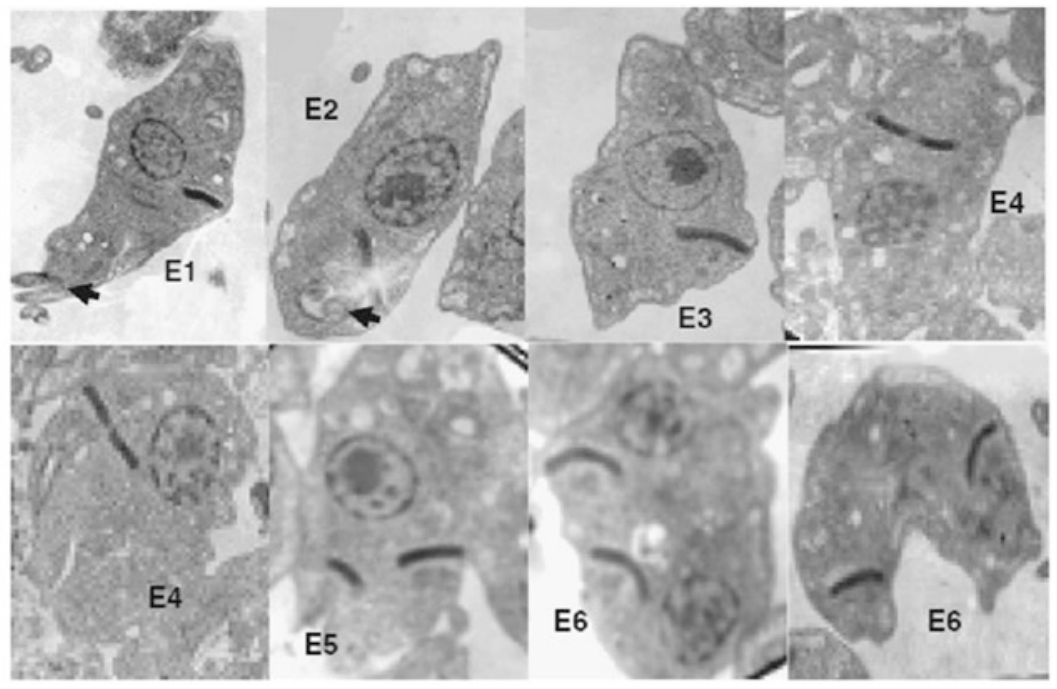



E1

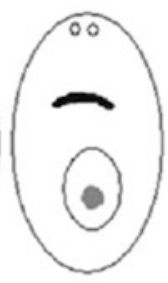

E2

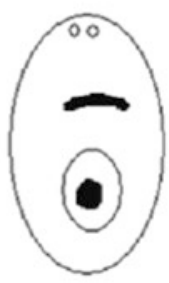

E3

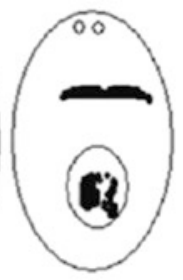

E4

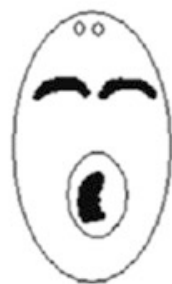

E5

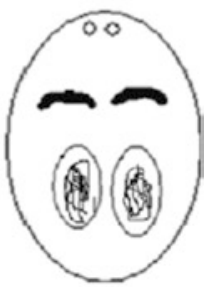

E6

Fig. 11.17 Ultrastructural aspects of Trypanosoma cruzi epimastigotes after $18 \mathrm{~h}$ of hydroxyurea (HU) removal. The figure shows the sequential stages during cell division, which are schematized in the bottom panel. FP flagellar pocket, $\mathrm{K}$ kinetoplast, $\mathrm{N}$ nucleus. Arrow: flagellum. Magnification: $\times 2000$ (Lozano et al. 2012a)

egy it has been possible to determine that around $18 \mathrm{~h}$ after synchronization, the events of the cell division of the parasites begin. Taking into account the number of flagella, kinetoplasts and chromatin condensation, six stages of parasites would be found, which have been ordered sequentially as shown in Fig. 11.17. From this assumption, we observed that the treatment with ICTX $(4.3 \mu \mathrm{M})$ interferes with early steps of the cell division. It is noteworthy that at $18 \mathrm{~h} 30 \mathrm{~min}$, a number of control parasites had progressed to the E6 stage, while most of the treated parasites remained in the E1 stage. This wave of division was maintained until $20 \mathrm{~h}$, and probably until $21 \mathrm{~h}$, since an increase of parasites in the E1 stage observed in the controls could be a possible E7 stage (occurring after cell division), which would be indistinguishable from E1 (Fig. 11.18).

More recently, a new diterpene, 12-hydroxy-11,14-diketo-6,8,12-abietatrien19,20-olide) (HABTO, $\mathrm{IC}_{50} \sim 14 \mu \mathrm{M}$ ) belonging to the abietane group and some derivatives, proved to be active against epimastigotes, inhibiting parasite growth 

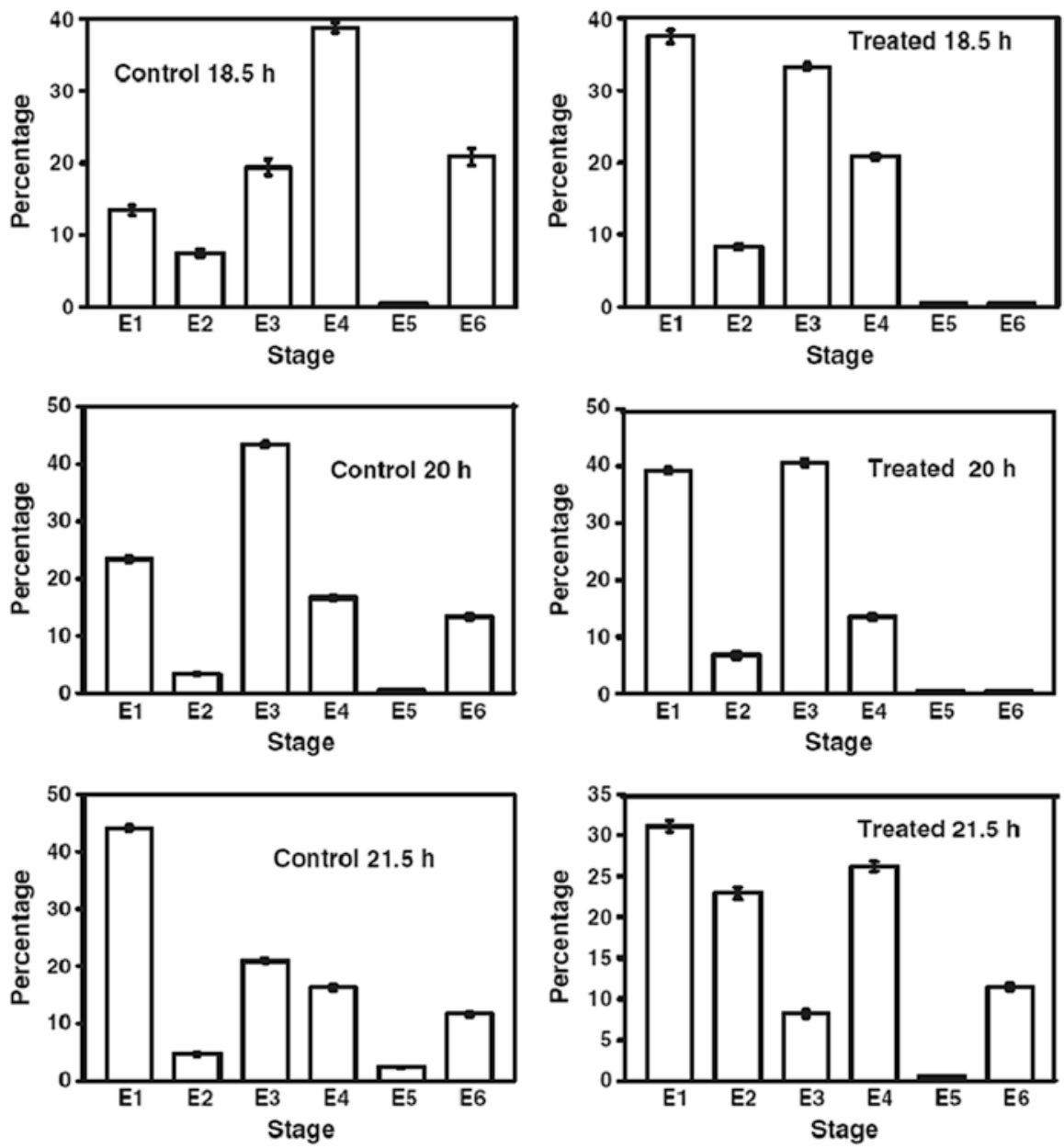

Fig. 11.18 Quantification of the different parasite stages in control cultures or in cultures treated with 5-epi-icetexone (ICTX) long after the removal of hydroxyurea (HU). Graphs show the distribution of each stage in control cultures and in cultures treated at different times $(18.5,20$, and $21.5 \mathrm{~h}$ after removal of $\mathrm{HU}$ ). Bars represent the percentages of each stage \pm SD from three independent experiments (Lozano et al. 2012a) 


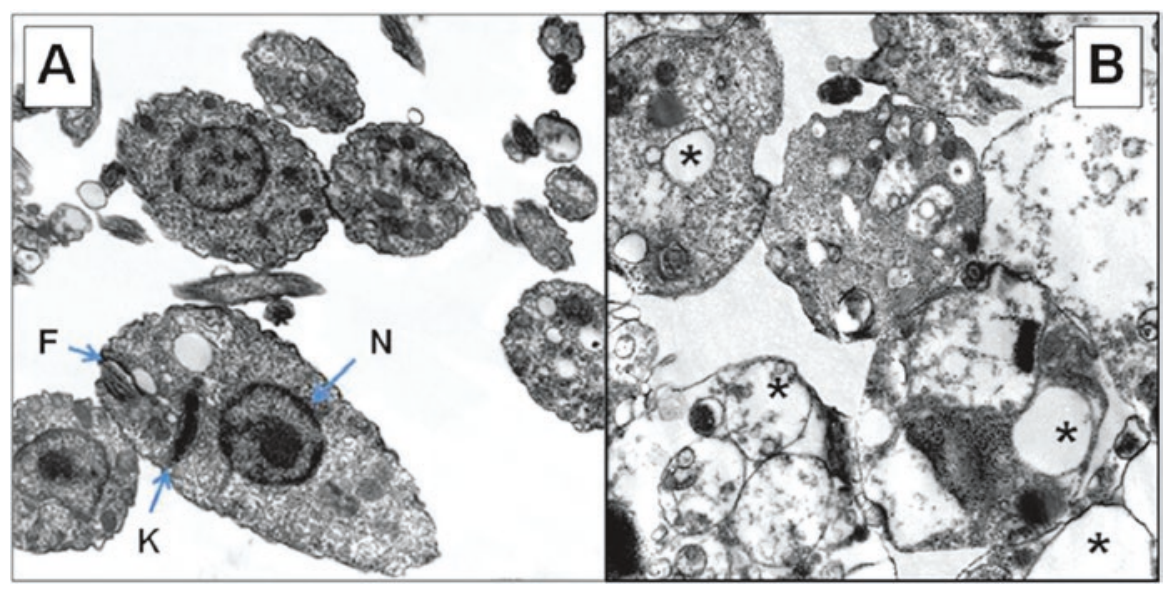

Fig. 11.19 The effect of 12-hydroxy-11,14-diketo-6,8,12-abietatrien-19,20-olide (HABTO) on the ultrastructure of Trypanosoma cruzi epimastigotes at $48 \mathrm{~h}$ of treatment. (a) Control culture and (b) culture treated with $14 \mu \mathrm{M}$ HABTO (N nucleus, K kinetoplast, F flagellum). Asterisks: vacuolization. Magnification: $\times 3000(\mathbf{a}) ; \times 3500$ (b) $($ Lozano et al. 2015)

(Lozano et al. 2015). As observed in Fig. 11.19, HABTO can induce an intense vacuolization similar to that observed with other terpenes.

\subsubsection{Effect of Sesquiterpene Lactones on Leishmania spp.}

DHL, MXN, and also helenalin (HLN) have also been found to be active against this trypanosomatid, since they inhibited parasite growth and induced strong vacuolization, HLN being more deleterious than the others (Fig. 11.20).

Leishmania amazonensis parasites treated with $1 \mu \mathrm{g} / \mathrm{ml}$ of parthenolide showed significant morphological alterations. An intense exocytic activity was observed in the region of the flagellar pocket, which appeared in the form of protrusions of the cell body toward the flagellar pocket and concentric membranes within the pocket (Fig. 11.21b, c). Moreover, some structures similar to large lysosomes were observed in the cytoplasm (Fig. 11.1d) (Tiuman et al. 2005).

De Toledo showed, for the first time, that Tithonia diversifolia dichloromethane leaf rinse extract (LRE) presents strong in vitro antileishmanial activity. Notably, LRE is a rich source of STL. The LRE showed a LD50 value of $1.5 \pm 0.50 \mu \mathrm{g} /$ $\mathrm{mL}$. Through scanning electron microscopy (SEM), morphological analysis of promastigotes revealed noticeable differences between the treated parasites and the control group (Fig. 11.22). When parasites were incubated with LRE, they lost two major promastigote characteristics: (i) their fusiform morphology changed to a rounded shape, and (ii) the flagellum in the majority of the cells was missing. All 

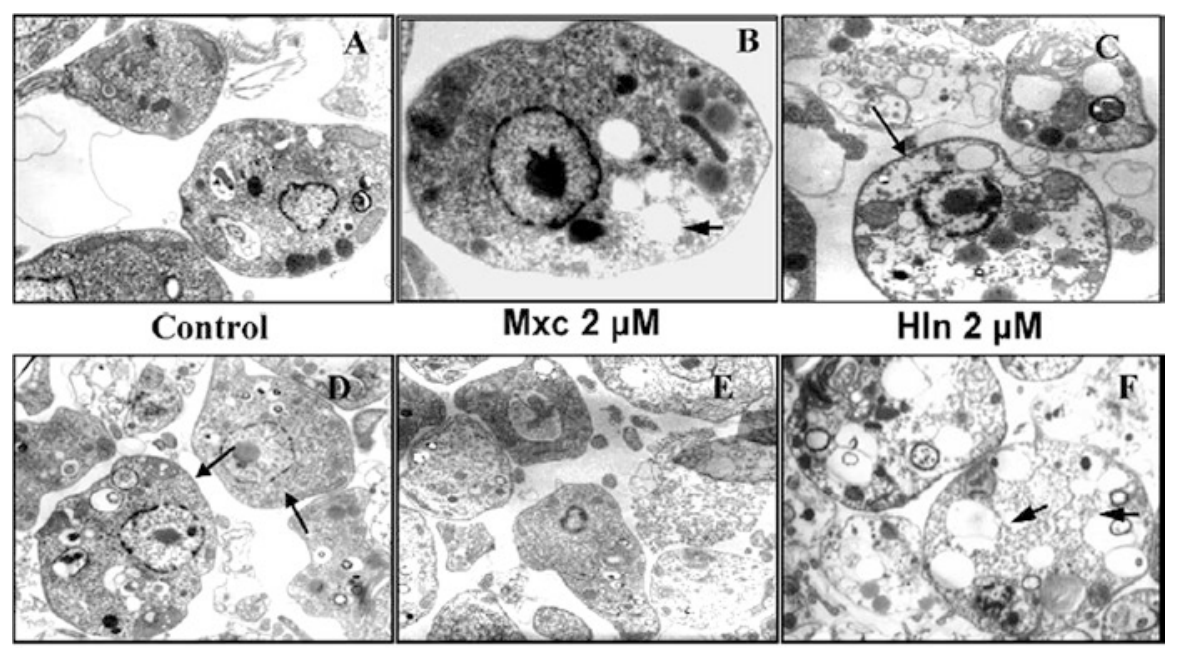

DhL $4 \mu \mathrm{M}$

$\mathrm{Mxc} 2 \mu \mathrm{M}$

HIn $2 \mu M$

Fig. 11.20 Ultrastructure of Leishmania mexicana after incubation with or without the STLs at the indicated concentrations. Parasites were incubated for $24(\mathbf{a}-\mathbf{c})$ or $48 \mathrm{~h}(\mathbf{d}-\mathbf{f})$ and then fixed and processed for TEM. Arrows, pericellular microtubules; arrowheads, vacuoles. Magnification: $\times 15,000(\mathbf{a}, \mathbf{c}, \mathbf{d}$, and f) $; \times 30,000(\mathbf{b}) ; \times 9,000(\mathbf{f})($ Barrera et al. 2008)

this information suggests that the LRE is a potential source of natural compounds with leishmanicidal activity.

Eight STL (Fig. 11.23), from LREs, were investigated for activity against promastigote forms of L. braziliensis (Table 11.1). STL $\mathbf{3}$ was the only compound that did not show an in vitro leishmanicidal effect in the evaluated concentrations and displayed an $\mathrm{LD}_{50}$ value that was higher than $50 \mu \mathrm{g} \cdot \mathrm{mL}-1$ (Table 11.1). Still, compounds 1,2 , and $4-8$ displayed very effective $\mathrm{LD}_{50}$ values ranging from $6.0 \pm 2.5$ to $37.4 \pm 7.1 \mu \mathrm{M}$ (see Table 11.1). The antiprotozoal activities, displayed by STL, correlate with their cytotoxicity, which are promoted by a Michael-type addition reaction of free thiol groups (usually from cysteine residues) from proteins with $\alpha, \beta$-unsaturated carbonyls from the $\alpha$-methylene- $\gamma$-lactone group. Cytotoxicity assays against macrophages for the effective compounds (Table 11.1) show that only compound 1 (tagitinin C), the major STL present in LRE, causes significant cytotoxic effects while displaying low selectivity $(\mathrm{SI}=1.4)$. Interestingly, the chemical structure of 1 (Fig. 11.23) has an $\alpha, \beta$-unsaturated carbonyl group in the $\gamma$-lactone ring and a carbonyl group conjugated with two different double bonds in the germacrane ring; therefore, there are three reactive sites. On the other hand, the other STL, which have only one or two $\alpha, \beta$-unsaturated carbonyl groups (compounds $4-8$ and 2 , respectively), did not show significant toxicity in macrophages and displayed a high level of selectivity (Table 11.1) (De Toledo et al. 2014). 

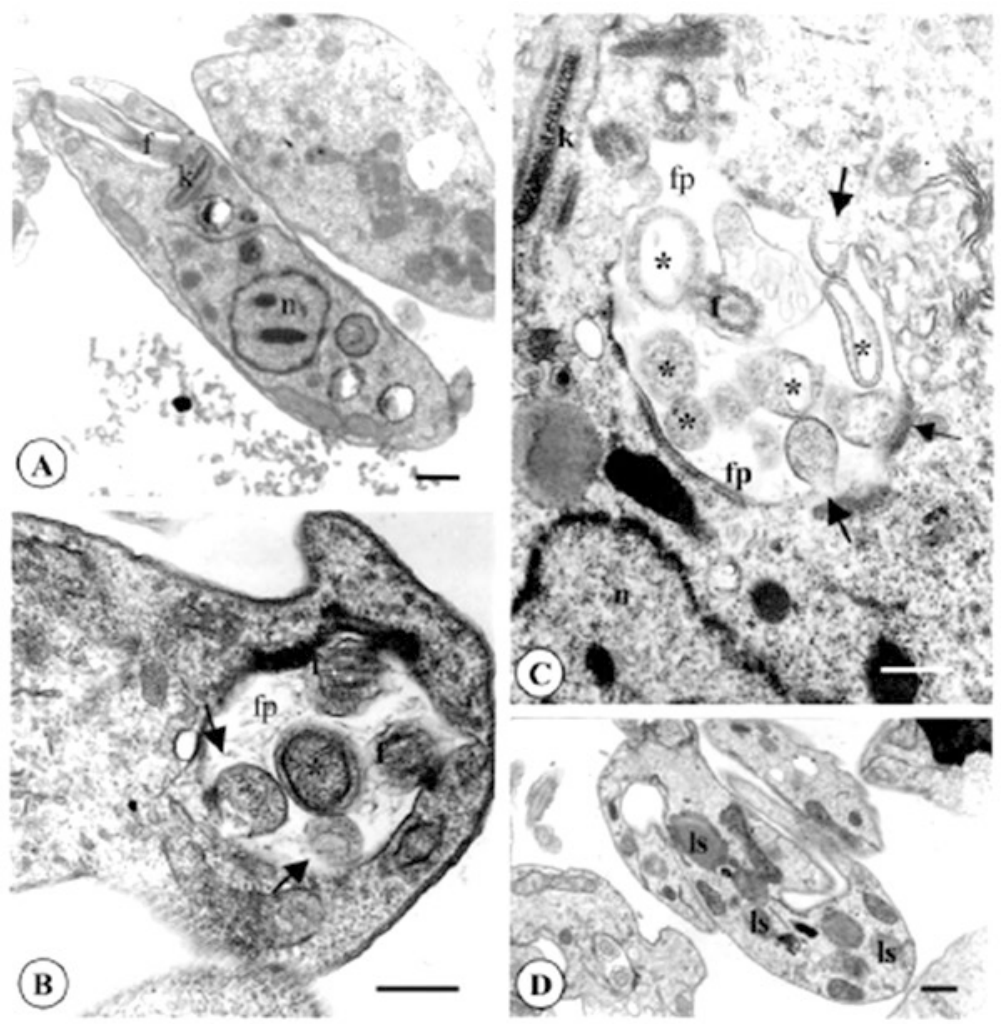

Fig. 11.21 Ultrastructural effects of parthenolide on promastigote forms of L. amazonensis. Parasites were incubated with DMSO or medium alone (a) or with $1 \mu \mathrm{g}$ of parthenolide/ml (the $\mathrm{IC}_{90}$ ) (b to d) for $72 \mathrm{~h}$. (a) Section showing the normal aspect of the nucleus, the flagellum in the flagellar pocket, and the mitochondrion containing the kinetoplast. (b and c) Promastigote showing intense exocytic activity. The arrows indicate the protrusions of the cell body toward the flagellar pocket; the asterisks indicate the vesicles located in the flagellar pocket. (d) The promastigotes also showed some structures similar to large lysosomes in the cytoplasm. fp flagellar pocket, $\mathrm{f}$ flagellum, k kinetoplast, $\mathrm{n}$ nucleus, ls lysosome. Bars, $1 \mu \mathrm{m}$ (Tiuman et al. 2005)


Fig. 11.22 Scanning electron microscopy of untreated (a) and $10 \mu \mathrm{g} / \mathrm{mL}$ Tithonia diversifolia dichloromethane leaf rinse extract (b) Leishmania braziliensis promastigotes. Bar, $5 \mu \mathrm{m}$ (De Toledo et al. 2014) 




1

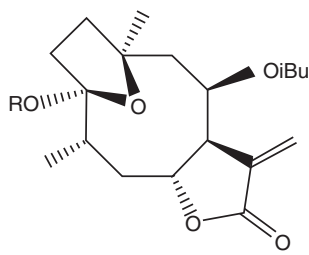

45

$\mathrm{ROH} \mathrm{OMe}$
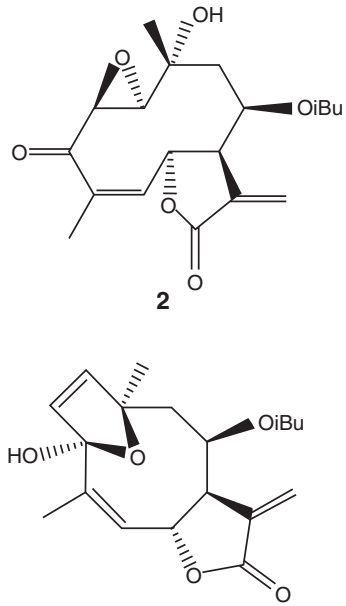

6

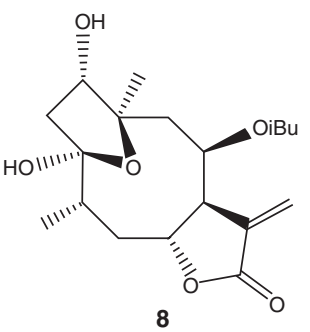

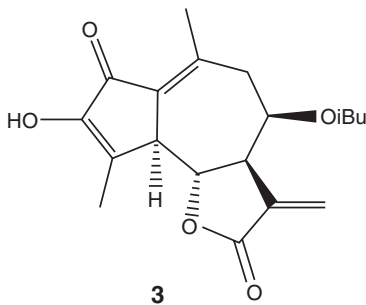

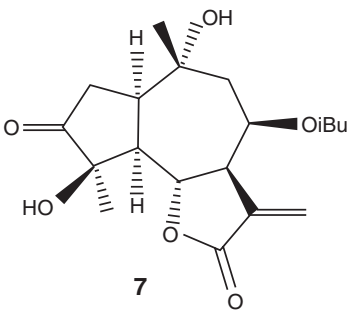

Fig. 11.23 Chemical structures of sesquiterpene lactones isolated from the leaves of Tithonia diversifolia

Table 11.1 In vitro antileishmanial activities of sesquiterpene lactones of Tithonia diversifolia against Leishmania braziliensis promastigotes and cytotoxic effects on peritoneal macrophages

\begin{tabular}{l|l|l|l}
\hline Compounds & $\begin{array}{l}\mathrm{LD}_{50} \text { for L. braziliensis } \mu \mathrm{g} . \mathrm{mL}^{-1} / \\
\mu \mathrm{M}\end{array}$ & $\begin{array}{l}\mathrm{LD}_{50} \text { for macrophages } \\
\mu \mathrm{g} . \mathrm{mL}^{-1}\end{array}$ & $\begin{array}{l}\text { Selectivity } \\
\text { index }\end{array}$ \\
\hline 1 & $3.2 \pm 0.5 / 9.2 \pm 1.4$ & $4.5 \pm 0.9$ & 1.4 \\
\hline 2 & $2.2 \pm 0.9 / 0.6 \pm 2.5$ & $>50.0$ & $>22.7$ \\
\hline 3 & $>50.0$ & $>50.0$ & - \\
\hline 4 & $8.7 \pm 1.9 / 24.7 \pm 5.4$ & $24.9 \pm 1.1$ & 2.9 \\
\hline 5 & $13.7 \pm 2.6 / 37.4 \pm 7.1$ & $>50.0$ & $>3.6$ \\
\hline 6 & $7.4 \pm 2.8 / 21.2 \pm 8.0$ & $>50.0$ & $>6.7$ \\
\hline 7 & $9.0 \pm 1.2 / 24.6 \pm 3.3$ & $>50.0$ & $>5.5$ \\
\hline 8 & $7.5 \pm 3.2 / 20.4 \pm 8.7$ & $>50.0$ & $>6.6$ \\
\hline
\end{tabular}




\subsection{Conclusion}

Taking into account all these findings, compounds from the terpene family emerge as promising alternatives for therapeutic use against parasitic diseases, and the studies on parasite ultrastructure became an important tool to elucidate the mechanisms of action and the identification of molecular targets for the drugs.

\section{References}

Aldunate J, Morello A (1993) Free radicals in the mode of action of parasitic drugs. In: Aruoma OI (ed) Free radicals in tropical diseases. Harwood Academic Publishers, London, pp 137-165

Andrade DV, Gollob KJ, Dutra WO (2014) Acute chagas disease: new global challenges for an old neglected disease. PLoS Negl Trop Dis 8:e3010. https://doi.org/10.1371/journal.pntd.0003010

Ariyanayagam MR, Fairlamb AH (2001) Ovothiol and trypanothione as antioxidants in trypanosomatids. Mol Biochem Parasitol 115:189-198

Ariyanayagam MR, Oza SL, Mehlert A et al (2003) Bis (glutathionyl) spermine and other novel trypanothione analogues in Trypanosoma cruzi. J Biol Chem 278:27612-27619

Avila JL, Avila A (1981) Trypanosoma cruzi: allopurinol in the treatment of mice with experimental acute Chagas disease. Exp Parasitol 5:204-208

Avila JL, Avila A, Monzón H (1984) Differences in allopurinol and 4- aminopyrazolo(3,4-d) pyrimidine metabolism in drug-sensitive and insensitive strains of Trypanosoma cruzi. Mol Biochem Parasitol 1:51-60

Barrera P, Jimenez-Ortiz V, Giordano O et al (2008) Natural sesquiterpene lactones are active against Leishmania mexicana possible by multiple effects. J Parasitol 94:1143-1149

Bergstrom JD, Dufresne C, Bills GF et al (1995) Discovery, synthesis and mechanism of action of the zaragozic acids: potent inhibitors of squalene synthase. Annu Rev Microbiol 49:607-639

Bontempi E, Cazzulo J (1990) Digestion of human immunoglobulin G by the major cysteine proteinase (cruzipain) from Trypanosoma cruzi. FEMS Microbiol Lett 58:337-341

Brack C (1968) Electron microscopic studies on the life cycle of Trypanosoma cruzi with special reference to developmental forms in the vector Rhodnius prolixus. Acta Trop 25:289-356

Brengio SD, Belmonte S, Guerreiro E et al (2000) The sesquiterpene lactone dehydroleucodine (DHL) affects the growth of cultured epimastigotes of Trypanosoma cruzi. J Parasitol 86:407-412

Campbell DA, Westenberger SJ, Sturm NR (2004) The determinants of Chagas disease: connecting parasite and host genetics. Curr Mol Med 4:549-562

Campetella O, Henriksson J, Aslund L et al (1992) The major cysteine proteinase (cruzipain) from Trypanosoma cruzi is encoded by multiple polymorphic tandemly organized genes located on different chromosomes. Mol Biochem Parasitol 50:225-234

Costantino VV, Lobos-Gonzalez L, Ibañez J et al (2016) Dehydroleucodine inhibits tumor growth in a preclinical melanoma model by inducing cell cycle arrest, senescence and apoptosis. Cancer Lett 372(1):10-23

Da Silva CF, Batista DGJ, De Araújo JS et al (2013) Activities of psilostachyin A and cynaropicrin against Trypanosoma cruzi in vitro and in vivo. Antimicrob Agents Chemother 57(11):5307-5314

De Souza W (2002) Basic cell biology of Trypanosoma cruzi. Curr Pharm Des 8:269-285

De Souza W (2008) Electron microscopy of trypanosomes - a historical view. Mem Inst Oswaldo Cruz 103(4):313-325

De Souza W (2009) Structural organization of Trypanosoma cruzi. Mem Inst Oswaldo Cruz 104:89-100 
De Souza W, Cavalcanti DP (2008) DNA-containing organelles in pathogenic protozoa: a review. Trends Cell Mol Biol 2:89-104

De Souza W, Meyer HJ (1975) An electron microscopic and cytochemical study of the cell coat of Trypanosoma cruzi in tissue cultures. Z Parasitenkd 46(3):179-187

De Souza W, Martinez-Palomo A, Gonzales-Robbles A (1978) The cell surface of Trypanosoma cruzi: cytochemistry and freeze-fracture. J Cell Sci 33:285-299

Dias JCP (1984) Acute Chagas' disease. Mem Inst Oswaldo Cruz 79(suppl):85-91

Dias JCP (1995) Natural history of Chagas' disease. Arq Bras Cardiol 65:359-366

Docampo R, De Souza W, Miranda K et al (2005) Acidocalcisomes - conserved from bacteria to man. Nat Rev Microbiol 3:251-261

Dos Reis F, Judice W, Juliano M et al (2006) The substrate specificity of cruzipain 2, a cysteine protease isoform from Trypanosoma cruzi. FEMS Microbiol Lett 259:215-220

Eakin AE, Mills AA, Harth G et al (1992) The sequence, organization, and expression of the major cysteine protease (cruzain) from Trypanosoma cruzi. J Biol Chem 267:7411-7420

El Sayed NM, Myler PJ, Blandin G et al (2005) Comparative genomics of trypanosomatid parasitic Protozoa. Science 309:404-409

Elias MCQB, Marques-Porto R, Freymuller E et al (2001) Transcription rate modulation through the Trypanosoma cruzi life cycle occurs in parallel with changes in nuclear organization. Mol Biochem Parasitol 112:79-90

Elias MC, Da Cunha JPC, De Faria FP et al (2007) Morphological events during the Trypanosoma cruzi cell cycle. Protist 158:147-157

Engel JC, Garcia CT, Hsieh I et al (2000) Upregulation of the secretory pathway in cysteine protease inhibitor-resistant Trypanosoma cruzi. J Cell Sci 113:1345-1354

Garcia ES, Azambuja P (1991) Development and interactions of Trypanosoma cruzi within the insect vector. Parasitol Today 7:240-244

Giordano OS, Guerreiro E, Pestchanker MJ et al (1990) The gastric cytoprotective effect of several sesquiterpene lactones. J Nat Prod 53:803-809. https://doi.org/10.1021/np50070a004

Giordano OS, Pestchanker MJ, Guerreiro E et al (1992) Structure-activity relationship in the gastric cytoprotective effect of several sesquiterpene lactones. J Med Chem 35:2452-2458

Gonzalez-Pacanowska D, Arison B, Havel CM et al (1988) Isopentenoid synthesis in isolated embryonic Drosophila cells. Farnesol catabolism and v-oxidation. J Biol Chem 263:1301-1306

Gutteridge WE, Davies MJ (1981) Enzymes of purine salvage in Trypanosoma cruzi. FEBS Lett 127:211-214

Hammond DJ, Gutteridge WE, Opperdoes FR (1981) A novel location for two enzymes of de novo pyrimidine biosynthesis in trypanosomes and Leishmania. FEBS Lett 128:27-29

Jimenez-Ortiz V, Brengio SD, Giordano O et al (2005) The trypanocidal effect of sesquiterpene lactones helenalin and mexicanin on cultured epimastigotes. J Parasitol 91:170-174

Johnston DA, Blaxter ML, Degrave WM (1999) Genomics and the biology of parasites. BioEssays 21:131-147

de Toledo J, Ambrósio S, Borges C, et al (2014) In Vitro Leishmanicidal Activities of Sesquiterpene Lactones from Tithonia diversifolia against Leishmania braziliensis Promastigotes and Amastigotes. Molecules 19 (5):6070-6079.

Kolien AH, Schaub GA (2000) The development of Trypanosoma cruzi in triatomine. Parasitol Today 16:381-387

Laranja FS, Dias E, Nobrega G et al (1956) Chagas' disease; a clinical, epidemiologic, and pathologic study. Circulation 14:1035-1060

Lazardi K, Urbina JA, De Souza W (1990) Ultrastructural alterations induced by two ergosterol biosynthesis inhibitors, ketoconazole and terbinafine, on epimastigotes and amastigotes of Trypanosoma (Schizotrypanun) cruzi. Antimicrob Agents Chemother 34:2097-2105

Lee KH, Hall IH, Mar EC et al (1977) Sesquiterpene antitumor agents: inhibitors of cellular metabolism. Science 196:533-535

Linder JC, Staehelin LA (1977) Plasma membrane specialization in a trypanosomatid flagellate. J Ultrastruct Res 60:246-262 
Lozano E, Barrera P, Tonn C et al (2012a) The effect of the diterpene 5-epi-icetexone on the cell cycle of Trypanosoma cruzi. Parasitol Int 61:275-279

Lozano E, Barrera P, Salinas R et al (2012b) Sesquiterpene lactones and the diterpene 5-epiicetexone affect the intracellular and extracellular stages of Trypanosoma cruzi. Parasitol Int 61:628-633

Lozano ES, Spina RM, Tonn CE et al (2015) An abietane diterpene from Salvia cuspidata and some new derivatives are active against Trypanosoma cruzi. Bioorg Med Chem Lett 25:5481-5484

Lozano E, Strauss M, Spina R et al (2016) The in vivo trypanocidal effect of the diterpene 5-epiicetexone obtained from Salvia gilliesii. Parasitol Int 65:23-26

Lukes J, Guilbride DL, Votýpka J et al (2002) Kinetoplast DNA network: evolution of an improbable structure. Eukaryot Cell 1:495-502

Majumder HK (2008) Drug targets in kinetoplastid parasites (Advances in experimental medicine and biology). Vol 625 ISBN: 978-0-387-77569-2 (Print) 978-0-387-77570-8 (Online), Springer Verlag, New York

Marr JJ, Berens RL, Nelson DJ (1978) Antitrypanosomal effect of allopurinol: conversion in vivo to aminopyrazolopyrimidine nucleotides by Trypanosoma cruzi. Science 201:1018-1020

Martinez-Palomo A, De Souza W, Gonzales-Robles AJ (1976) Topographical differences in the distribution of surface coat components and intramembranous particles. J Cell Biol 69:507-513

Maya JD, Repetto Y, Agosin M et al (1997) Effects of nifurtimox and benznidazole upon glutathione and trypanothione content in epimastigote, trypomastigote and amastigote forms of Trypanosoma cruzi. Mol Biochem Parasitol 86:101-106

McKerrow J, Caffrey C, Kelly B et al (2006) Proteases in parasitic diseases. Annu Rev Pathol $1: 497-536$

Meirelles M, Juliano L, Carmona E et al (1992) Inhibitors of the major cysteinyl proteinase (GP57/51) impair host cell invasion and arrest the intracellular development of Trypanosoma cruzi in vitro. Mol Biochem Parasitol 52:175-184

Meyer H, Porter KR (1954) A study of Trypanosoma cruzi with the electron microscope. Parasitology 44:1-2

Meyer H, Oliveira Musacchio M, Andrade Mendonça I (1958) Electron microscopy study of Trypanosoma cruzi in thin sections of infected tissue cultures and blood agar forms. Parasitology 48:1-8

Miranda K, Benchimol M, Docampo R et al (2000) The fine structure of acidocalcisomes in Trypanosoma cruzi. Parasitol Res 86:373-384

Miranda K, Docampo R, Grillo O et al (2004) Acidocalcisomes of trypanosomatids have speciesspecific elemental composition. Protist 155:395-340

Montalvetti A, Rohloff P, Docampo R (2004) A functional aquaporin co-localizes with the vacuolar proton pyrophosphatase to acidocalcisomes and the contractile vacuole complex of Trypanosoma cruzi. J Biol Chem 279:38673-38682

Mottram J, Brooks D, Coombs G (1998) Roles of cysteine proteinases of trypanosomes and Leishmania in host-parasite interactions. Curr Opin Microbiol 1:455-460

Muschietti LV, Sülsen VP, Martino V (2008) Trypanocidal and leishmanicidal activities of south American medicinal plants. In: Martino VS, Muschietti LV (eds) South American medicinal plants as a potential source of bioactive compounds. Transworld Research, Kerala, pp 149-180

Nieto M, Garcia EE, Giordano OS et al (2000) Icetexane and abietane diterpenoids from Salvia gilliessi. Phytochemistry 53:911-915

Ogbadoiyi EO, Robinson DR, Gull K (2003) A high-order trans-membrane structural linkage is responsible for mitochondrial genome positioning and segregation by flagellar basal bodies in trypanosomes. Mol Biol Cell 14:1769-1779

Opperdoes FR (1987) Compartmentalization of carbohydrate metabolism in trypanosomes. Annu Rev Microbiol 41:127-151

Opperdoes FR, Borst P (1977) Localization of nine glycolytic enzymes in a microbody-like organelle in Trypanosoma brucei. FEBS Lett 80:360-364

Opperdoes FR, Cotton D (1982) Involvement of the glycosome of Trypanosoma brucei in carbon dioxide fixation. FEBS Lett 143:60-64 
Penissi AB, Rudolph MI, Piezzi RS (2003) Role of mast cells in gastrointestinal mucosal defense. Biocell 27(2):163-172

Pimenta PF, De Souza WJ (1983) Leishmania mexicana amazonensis: surface charge of amastigote and promastigote forms. Exp Parasitol 56(2):194-206

Pinto AY, Ferreira AG Jr, Valente Vda C et al (2009) Urban outbreak of acute Chagas disease in Amazon region of Brazil: four-year follow-up after treatment with benznidazole. Rev Panam Salud Pública 25:77-83

Rassi A, Luquetti AO (1992) Therapy of Chagas disease. In: Wendel S, Brener Z, Camargo ME, Rassi A (eds) Chagas disease (American Trypanosomiasis): its impact on transfusion and clinical medicine. ISBT, Sao Paulo, pp 237-247

Sánchez AM, Jiménez-Ortiz V, Sartor T et al (2006) A novel icetexane diterpene, 5-epi-icetexone from Salvia gilliessi is active against Trypanosoma cruzi. Acta Trop 98:118-124

Sepúlveda-Boza S, Cassels BK (1996) Plant metabolites active against Trypanosoma cruzi. Planta Med 62:98-105

Shapiro TA, Englund PT (1995) The structure and replication of kinetoplast DNA. Annu Rev Microbiol 49:117-143

Simpson L (1972) The kinetoplast DNA of the hemoflagellate protozoa. Int Rev Cytol 32:139-207

Solari AJ (1980) The 3-dimensional fine structure of the mitotic spindle in Trypanosoma cruzi. Chromosoma 78:239-255

Souto-Padron T, De Souza W (1978) Ultrastructural localization of basic proteins in Trypanosoma cruzi. J Histochem Cytochem 26:349-356

Souto-Padron T, De Souza W (1979) Cytochemical analysis at the fine-structural level of trypanosomatids stained with phosphotungstic acid. J Protozool 26:551-557

Souto-Padron T, De Souza W, Heuser JE (1984) Quick-freeze, deep-etch rotary replication of Trypanosoma cruzi and Herpetomonas megaseliae. J Cell Sci 69:167-168

Souto-Padron T, Campetella O, Cazzulo J et al (1990) Cysteine proteinase in Trypanosoma cruzi: immunocytochemical localization and involvement in parasite-host cell interaction. J Cell Sci 96:485-490

De Souza W (1999) A short review on the morphology of Trypanosoma cruzi: from 1909 to 1999. Mem Inst Oswaldo Cruz 94(Suppl) I:17-36

Sülsen VP, Güida C, Coussio J et al (2006) In vitro evaluation of trypanocidal activity in plants used in argentine traditional medicine. Parasitol Res 98:370-374

Sülsen V, Barrera P, Muschietti L et al (2010) Antiproliferative effect and Ultrastructural alterations induced by Psilostachyin on Trypanosoma cruzi. Molecules 15:545-553. https://doi. org/10.3390/molecules 15010545

Sülsen VP, Frank FM, Cazorla SI et al (2011) Psilostachyin C: a natural compound with trypanocidal activity. Int J Antimicrob Agents 37:536-543

Tiuman TS, Ueda-Nakamura T, Garcia Cortez DA et al (2005) Antileishmanial activity of parthenolide, a sesquiterpene lactone isolated from Tanacetum parthenium. Antimicrob Agents Chemother 49(1):176-182

Turrens JF (2004) Oxidative stress and antioxidant defenses: a target for the treatment of diseases caused by parasitic protozoa. Mol Asp Med 25:211-220

Urbina JA (1997) Lipid biosynthesis pathways as chemotherapeutic targets in kinetoplastid parasites. Parasitology 117:S91-S99

Urbina JA (2000) Sterol biosynthesis inhibitors for Chagas' disease. Curr Opin Anti-Infect Inv Drugs 2:40-46

Urbina JA (2001) Specific treatment of Chagas disease: current status and new developments. Curr Opin Infect Dis 14:733-741

Urbina JA (2002) Chemotherapy of Chagas disease. Curr Pharm Des 8:287-295

Webster P, Russel DG (1993) The flagellar pocket of trypanosomatids. Parasitol Today 9:201-206 
Wilkinson SR, Kelly JM (2003) The role of glutathione peroxidases in trypanosomatids. Biol Chem 384:517-525

World Health Organization (WHO) (2002) Control of Chagas' disease. Tech Rep Ser 905:i-vi. World Health Organization, Geneva

World Health Organization (WHO) (2017) Chagas disease (American trypanosomiasis). Fact sheetUpdated March 2017. http://www.who.int/mediacentre/factsheets/fs340/en/. Accessed 2 Nov 2017

Zeledón R, Alvarenga NJ, Schosinsky K (1977) Ecology of Trypanosoma cruzi in the insect vector. In: Pan American Health Organization (ed) Chagas' Disease. Scientific Publication No. 347, Pan American Health Organization, Washington, pp 59-70 